\title{
Efferent Actions in the Chinchilla Vestibular Labyrinth
}

\author{
Vladimir Marlinski, Meir Plotnik, and Jay M. Goldberg \\ Department of Neurobiology, Pharmacology and Physiology, University of Chicago, 947 E. 58th Street, \\ Chicago, IL 60637, USA
}

Received: 21 July 2003; Accepted: 28 October 2003; Online publication: 4 March 2004

\section{ABSTRACT}

Efferent fibers were electrically stimulated in the brain stem, while afferent activity was recorded from the superior vestibular nerve in barbiturate-anesthetized chinchillas. We concentrated on canal afferents, but otolith afferents were also studied. Among canal fibers, calyx afferents were recognized by their irregular discharge and low rotational gains. In separate experiments, stimulating electrodes were placed in the efferent cell groups ipsilateral or contralateral to the recording electrode or in the midline. While single shocks were ineffective, repetitive shock trains invariably led to increases in afferent discharge rate. Such excitatory responses consisted of fast and slow components. Fast components were large only at high shock frequencies $(200-333 / \mathrm{s})$, built up with exponential time constants $<0.1 \mathrm{~s}$, and showed response declines or adaptation during shock trains $>1 \mathrm{~s}$ in duration. Slow responses were obtained even at shock rates of $50 / \mathrm{s}$, built up and decayed with time constants of 15-30 s, and could show little adaptation. The more regular the discharge, the larger was the efferent response of an afferent fiber. Response magnitude was proportional to $\mathrm{Cv}^{* b}$, a normalized coefficient of interspike-interval variation $\left(\mathrm{cv}^{*}\right)$ raised to the power $b=0.7$. The value of the exponent $b$ did not depend on unit type (calyx vs. bouton plus dimorphic, canal vs. otolith) or on stimulation site (ipsilateral, contralateral, or midline). Responses were slightly smaller with contralateral or midline stimulation than with ipsilateral stimulation, and they were smaller for otolith, as compared to canal, fibers.

Correspondence to: Vladimir Marlinski - Department of Neurobiology, Pharmacology and Physiology • University of Chicago 947 E. 58th Street - Chicago, IL 60637 - Telephone: (773) 702-3736; Fax: (773) 702-3736; email: vmarlins@midway.uchicago.edu
An anatomical study had suggested that responses to contralateral afferent stimulation should be small or nonexistent in irregular canal fibers. The suggestion was not confirmed in this study. Contralateral responses, including the large responses typically seen in irregular fibers, were abolished by shallow midline incisions that should have severed crossing efferent axons.

Keywords: vestibular labyrinth, efferent actions, electrical stimulation, semicircular canals, otolith organs, discharge regularity

\section{INTRODUCTION}

Most hair cell organs receive an efferent innervation originating in the brain stem (Rasmussen 1946; Warr 1975; Meredith 1988; Goldberg et al. 1999). In this regard, vestibular organs are not exceptional (Gacek 1960; Gacek and Lyon 1974; Warr 1975; Goldberg and Fernàndez 1980). Efferent fibers synapse on vestibular hair cells and on calyx endings and other afferent processes (Smith and Rasmussen 1968; Iurato et al. 1972; Wersäll and Bagger-Sjöbäck 1974; Lysakowski 1996; Lysakowski and Goldberg 1997).

To study efferent actions, afferent activity has been recorded during electrical stimulation of efferent pathways. In the case auditory or vibratory receptors, the predominant efferent action so produced is an inhibition of afferent activity (Wiederhold and Kiang 1970; Flock and Russell 1973; 1976; Furukawa 1981; Ashmore and Russell 1982; Art et al. 1984). More heterogeneous responses have been seen in vestibular organs of frogs (Rossi et al. 1980, 1994; Bernard et al. 1985; Sugai et al. 1991) and turtles (Brichta and 
Goldberg 2000) and include both increases and decreases in afferent discharge. In the toadfish, the predominant effect is an increase in afferent discharge (Boyle and Highstein 1990; Boyle et al. 1991). Studies in the squirrel monkey (Goldberg and Fernández 1980) and cat (McCue and Guinan 1994) have shown that the main efferent actions in mammals are excitatory. Responses differ depending on the discharge regularity of the afferent (Goldberg and Fernández 1980). In irregularly discharging afferents responses can be large, increasing the background discharge by as much as 100 spikes/s. The increase consists of a fast excitation with a time constant of 10-100 ms and a slow excitation with kinetics measured in seconds. In regular units, responses are smaller $(<10$ spikes/s) and mainly slow.

A purpose of the present study was to determine if similar results could be obtained in a rodent species, which could then provide a convenient model for further studies of efferent actions. Among rodents, we chose the chinchilla because extensive studies of the vestibular periphery in this species have provided information about the morphology (Fernández et al. 1988, 1990; Lysakowski and Goldberg 1997), physiology (Baird et al. 1988; Goldberg et al. 1990a), and morphophysiology (Baird et al. 1988; Goldberg et al. $1990 \mathrm{~b})$ of its afferent innervation and about the morphology of its hair cells (Lysakowski and Goldberg 1997) and of its efferent innervation (Smith and Rasmussen 1968; Marco et al. 1993; Ishiyama et al. 1994; Bridgeman et al. 1996; Lysakowski and Goldberg 1997; Lysakowski and Singer 2000).

Besides the practical need for a new animal model, two more theoretical considerations prompted the study. In the original work in the squirrel monkey efferent system (Goldberg and Fernández 1980), the two classes of morphologically distinct irregularly discharging afferents were not distinguished. The two classes are calyx afferents innervating type I hair cells and dimorphic afferents supplying both type I and type II hair cells. Both classes innervate the central zone of the crista (Baird et al. 1988) and the macular striola (Goldberg et al. 1990b). In the present study, we took advantage of the fact that calyx afferents innervating the crista can be recognized by their distinctive discharge properties without the need for intra-axonal labeling (Baird et al. 1988; Lysakowski et al. 1995). The second reason was prompted by the anterograde labeling of efferent neurons in the gerbil by Purcell and Perachio (1997b), who found that neurons located in the brain stem ipsilateral to the labyrinth preferentially innervated the central zone of the crista, whereas contralateral efferents preferentially supplied peripheral zones. Based on the regional organization of the crista (Baird et al. 1988; Lysakowski et al. 1995), electrical stimulation of ef- ferent fibers in the midline or on the contralateral side might be expected to mainly affect regularly discharging afferents. The expectation is inconsistent with observations in the squirrel monkey that afferents were affected similarly whether stimulation was contralateral, in the midline, or on the ipsilateral side (Goldberg and Fernández 1980) and with observations in the cat that large efferent responses were obtained from irregular fibers with midline stimulation (McCue and Guinan 1994). A possible explanation for the discrepancy is that the anatomical arrangement discovered by Purcell and Perachio (1997b) exists in rodents, but not in the monkey or cat. For this reason, the effects of stimulation at different sites were examined in the present experiments.

\section{METHODS}

\section{Animal preparation}

Experiments were done in chinchillas $(C$. lanigera) of either sex weighing 400-600 g. After an intramuscular injection of atropine sulfate $(25 \mu \mathrm{g})$ and acepromazine $(0.3 \mathrm{ml} / \mathrm{kg})$, animals were anesthetized with a solution containing 10\% 5,5-diallylbarbituric acid, $40 \%$ urethane, and $40 \%$ monoethyl urea $(0.3 \mathrm{ml} / \mathrm{kg}$ IP $)$. The superior branch of the left VIIIth nerve was exposed by an extracranial approach (Baird et al. 1988). A plexiglass recording chamber was cemented to the skull. $\mathrm{Ag}-\mathrm{AgCl}$ stimulating electrodes were implanted on the round window and in the floor of the middle ear on the left side. Throughout the experiment, rectal temperature was kept at $36-38^{\circ} \mathrm{C}$. Aspiration of the cerebellar vermis exposed the floor of the fourth ventricle, which was covered with warm mineral oil. The animal was placed in a superstructure in which the whole body could be tilted about pitch-and-roll axes with respect to the horizontal platform of a rotator. A velocity servo (Inland, Pittsburgh, PA, model 823) controlled the motion of the rotator. In the zero-tilt position, the animal was prone with the plane of the horizontal canal near the horizontal (motion) plane.

A stimulating array, held in a three-dimensional micromanipulator, was advanced into the brain stem. The array consisted of four tungsten wires, electrolytically sharpened and insulated to within $0.25 \mathrm{~mm}$ of their tips. The electrodes were spaced $0.5 \mathrm{~mm}$ apart in a parasagittal plane. In different experiments the array was placed in the midline or $1.5 \mathrm{~mm}$ laterally ipsilateral or contralateral to the recording site. For lateral placements, the sulcus limitans served as a landmark (Fig. 1). The most caudal stimulating electrode was positioned $2-3 \mathrm{~mm}$ rostral to the obex and the array was advanced $0.5-1 \mathrm{~mm}$ into the brain 


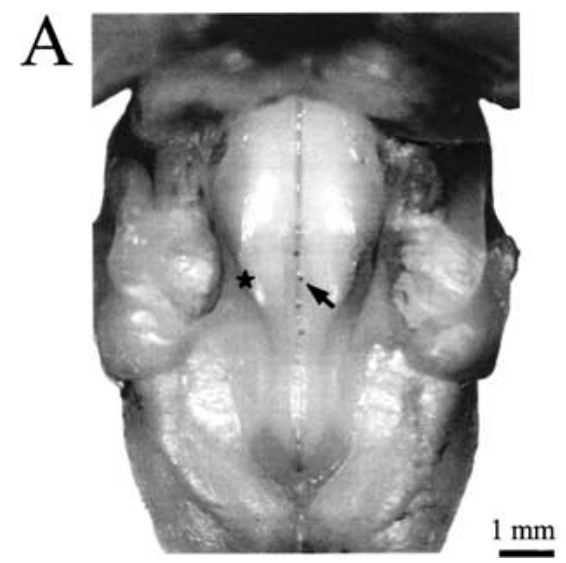

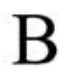

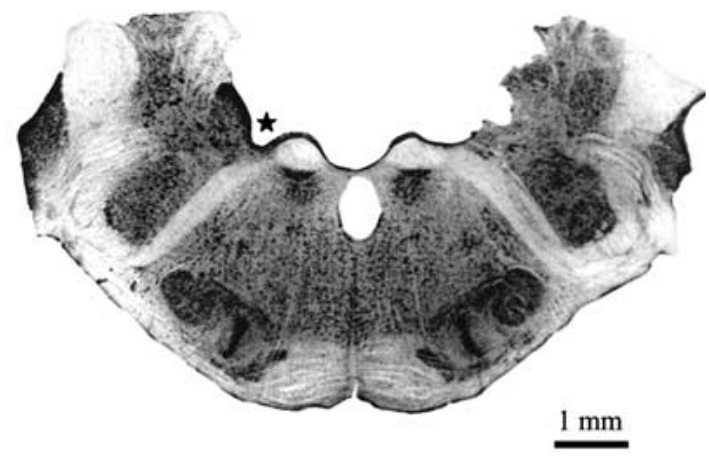

FIG. 1. A Photograph of the brain stem and fourth ventricle in an animal with a midline placement of stimulating electrodes. Locations of the four electrodes, including the most effective one (arrow), are seen. B A cross-section from the same brain with an electrolytic lesion made with the most effective stimulating electrode. In each panel, a star marks the groove of the sulcus limitans, which serves as a landmark since it is just dorsal to the efferent cell group. stem. Experimental procedures were approved by the University of Chicago Institutional Animal Care and Use Committee.

\section{Physiological testing}

Recording micropipettes were filled with $3 \mathrm{M} \mathrm{NaCl}$ and had impedances of $15-30 \mathrm{M} \Omega$. They were advanced into the nerve with a manual microdrive attached to the plexiglass chamber. Neural activity was monitored with a negative-capacitance preamplifier coupled to an amplifier with the gain 100 mounted near the animal (Biomedical Engineering, Thornwood, NY). The output of the amplifier and other signals were passed through slip rings. Experiments and data collection were controlled by custom programs run on a 386 computer.

Once an afferent was isolated, a series of manual rotations and tilts was used to determine which organ it innervated (Goldberg and Fernández 1975). As recordings were confined to the superior vestibular nerve, no posterior canal afferents were encountered. Rotation-sensitive units innervated either the horizontal (HC) or the superior (SC) canals. Units responding to tilts but not to rotations were classified as otolith (OTO) units. Based on the recording location in the superior nerve, most OTO units might be expected to innervate the utricular macula, although some might supply the anterior part of the saccular macula (Wersäll and Bagger-Sjöbäck 1974).

$\mathrm{HC}$ and OTO units were studied in the zero-tilt position. For SC units, the animal was first tilted $30^{\circ}$ nose-down and $30^{\circ}$ right-ear-down to bring the left superior-canal plane partly into the plane of motion. A 5-s sample of background activity was recorded and was used offline to compute a coefficient of interspike-interval variation $\left(\mathrm{cv}^{*}\right)$, normalized to a mean interval of $15 \mathrm{~ms}$ (Baird et al. 1988). For HC and SC fibers, responses to sinusoidal rotations $(2 \mathrm{~Hz}$, $20 \mathrm{deg} / \mathrm{s}, 64$ cycles) were used to calculate gains and phases. Gains of SC fibers were multiplied by a factor of $1 / \cos (\theta)=1.52$, where $\theta=49^{\circ}$ was the approximate angle between the superior-canal and motion planes after tilting. In several units, we studied the excitatory response to a 5 -s, $50-\mu \mathrm{A}$ galvanic stimulus delivered between the round-window and middle-ear electrodes with the round-window electrode serving as the cathode.

Efferent pathways were stimulated with trains of $100-\mu$ s constant-current shocks delivered between two adjacent electrodes of the stimulating array from a stimulus isolator (World Precision Instruments, Sarsota, FL, WPI 1850). Current magnitude was monitored as a voltage drop across a $10-\mathrm{k} \Omega$ resistor placed in series in the return (anodal) pathway. To record afferent activity during shock trains, the associated shock artifacts were canceled online (see Brichta and Goldberg 2000 for details). The electrode pair and their polarity were chosen and the depth of the array in the brain stem was adjusted to maximize the responses obtained from the first few units encountered in each animal.

Unless otherwise stated results are expressed as means \pm SEM, and two-tailed $t$ tests, corrected when necessary for unequal variances, were used to test for between-group differences. Statistical tests were done in SYSTAT for the Macintosh. Nonlinear regressions were calculated in Igor Pro using the MarquardtLevenberg algorithm. The quadratic discriminant function of Figure 2 was calculated from the dye-filled units in Baird et al. (1988). Based on their morphology, the units were assigned to the calyx (C) or noncalyx (NC, bouton plus dimorphic) class. The units were characterized by $x_{1}=\log _{10}\left(\mathrm{cv}^{*}\right)$ and $x_{2}=\log _{10}$ (gain), where gain was calculated from the responses to our standard $2-\mathrm{Hz}$ rotation. The two-dimensional vectors $\mathbf{x}=\left(x_{1}, x_{2}\right)$ for each unit were used to calculate a scalar score, $g(\mathbf{x})$, from a standard formula (Morrison 1990, p. 276, equation 3). Extracellularly recorded units were assigned to $\mathrm{C}$ if $g(\mathbf{x})>0$ and to NC otherwise. The curve seen in Figure 2 is the solution to $g(\mathbf{x})=0$. 


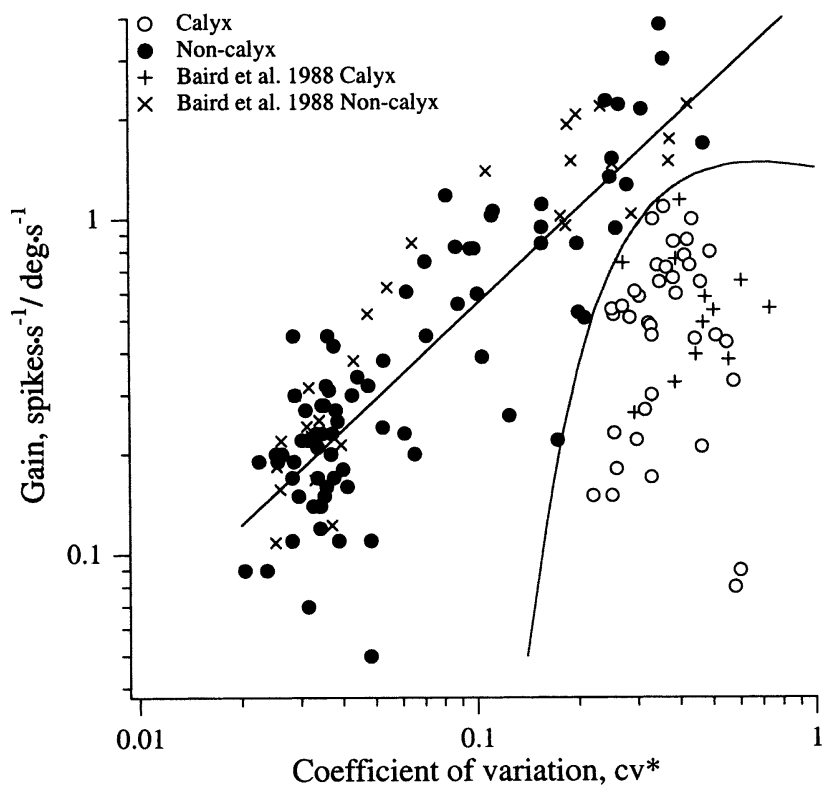

FIG. 2. Semicircular canal afferents can be categorized as calyx or noncalyx units by their discharge properties. Shown is the relation between the gain in response to $2-\mathrm{Hz}, 20-\mathrm{deg} / \mathrm{s}$ sinusoidal rotations and discharge regularity, the latter measured by a normalized coefficient of variation $\left(\mathrm{Cv}^{*}\right)$. Labeled calyx $(+)$ and noncalyx $(\mathrm{x})$ afferents from Baird et al. (1998) were used to construct the curved line, a quadratic discriminant function, which was then used to classify the unlabeled units of the present study as calyx $(\bigcirc)$ or noncalyx $(\bullet)$. Gains of noncalyx units related to $\mathrm{Cv}^{*}$ by a power law (straight line).

\section{Histological controls}

The position of the most effective brain-stem-stimulating electrode was marked in selected animals by an electrolytic lesion. At the end of the experiment, all animals were given an overdose of sodium pentobarbital. Animals chosen for histological examination were perfused transcardially with $250 \mathrm{ml}$ of physiological solution followed by the same amount of $2.5 \%$ paraformaldehyde-2.5\% glutaraldehyde in $0.1 \mathrm{M}$ phosphate buffer ( $\mathrm{pH}$ 7.4). The head was immersed in fixative solution for $24 \mathrm{~h}$ and in the fixative solution to which $30 \%$ sucrose had been added for another $24 \mathrm{~h}$. Transverse frozen serial sections of the brain stem were cut at $80 \mu \mathrm{m}$ and stained with $1 \%$ neutral red.

\section{RESULTS}

Conclusions are based on 118 canal units recorded in 29 animals. Fibers innervated the horizontal (HC, $n=88$ ) or superior canals (SC, $n=30$ ). Results from an additional 24 otolith (OTO) fibers are summarized in a separate section. Stimulation was on the ipsilateral side in 11 animals, in the midline in 9 animals, and on the contralateral side in 9 animals. A midline placement of the stimulating array is illus- trated in Figure 1 (arrow) and a lateral placement is depicted in Figure 11b. In the 15 brains examined histologically, the most effective stimulating electrode was located at anterior-posterior midlevel of the facial genu. Lateral placements were just medial to the vestibular nuclei, in the location of the main efferent cell group, the so-called group e (Marco et al. 1993; Bridgeman et al. 1996; Lysakowski and Singer 2000). Midline placements were at the same anterior-posterior level of the brain stem, just beneath the floor of the IVth ventricle, in a position where efferent fibers cross the midline (Lysakowski and Singer 2000).

\section{Distinguishing calyx and noncalyx units}

By the intra-axonal labeling of physiologically characterized afferents, Baird et al. (1988) showed that calyx units innervating the semicircular canals could be recognized by their irregular discharge and low rotational gains. Using the same population of labeled canal units, we derived a quadratic disciminant function based on the normalized coefficient of variation $\left(\mathrm{cv}^{*}\right)$ and the rotational gain (Fig. 2, curved line), which correctly assigned all 14 calyx and 28 noncalyx units of the original study. Here and elsewhere, we include both bouton and dimorphic units in the non-calyx category.

The same function was used to assign the canal units of the present study to the same two categories. Of the 118 canal units, $38(32 \%)$ were placed in the calyx class. As indicated by the straight line in Figure 2, calculated from the present sample, the rotational gains of noncalyx units were related to the $\mathrm{Cv}^{*}$ by a power law, gain $=a \cdot \mathrm{cv}^{* b}$ with $a=0.69 \pm 0.09$ spikes $\mathrm{s}^{-1} / \mathrm{deg} \mathrm{s}^{-1}$ and $b=0.94 \pm 0.07$. The power law is statistically indistinguishable from a linear relation or from the relation previously obtained by Baird et al. (1988). Calyx units in our study had a mean $\mathrm{Cv}^{*}$ of $0.38 \pm 0.02$. Substituting the mean value into the power law for noncalyx units gives a predicted gain for calyx units of 1.93 spikes $\mathrm{s}^{-1} / \mathrm{deg} \mathrm{s}^{-1}$, about four times the actual mean gain of $0.52 \pm 0.04$ spikes s $\mathrm{s}^{-1} / \mathrm{deg} \mathrm{\textrm {s } ^ { - 1 }}$.

Calyx units are relatively homogeneous in their discharge properties. They are the most irregularly discharging units in the sample and have distinctively low rotational gains. Noncalyx units are more heterogeneous, with many of their discharge properties being correlated with discharge regularity (Goldberg $2000)$. Because of the correlation, it is convenient to divide noncalyx units into regular $\left(\mathrm{cv}^{*} \leq 0.05\right)$ and nonregular $\left(\mathrm{cv}^{*} \leq 0.05\right)$ categories.

\section{Responses to electrical stimulation of efferent pathways}

As was the case for the squirrel monkey (Goldberg and Fernández 1980) and the cat (McCue and 


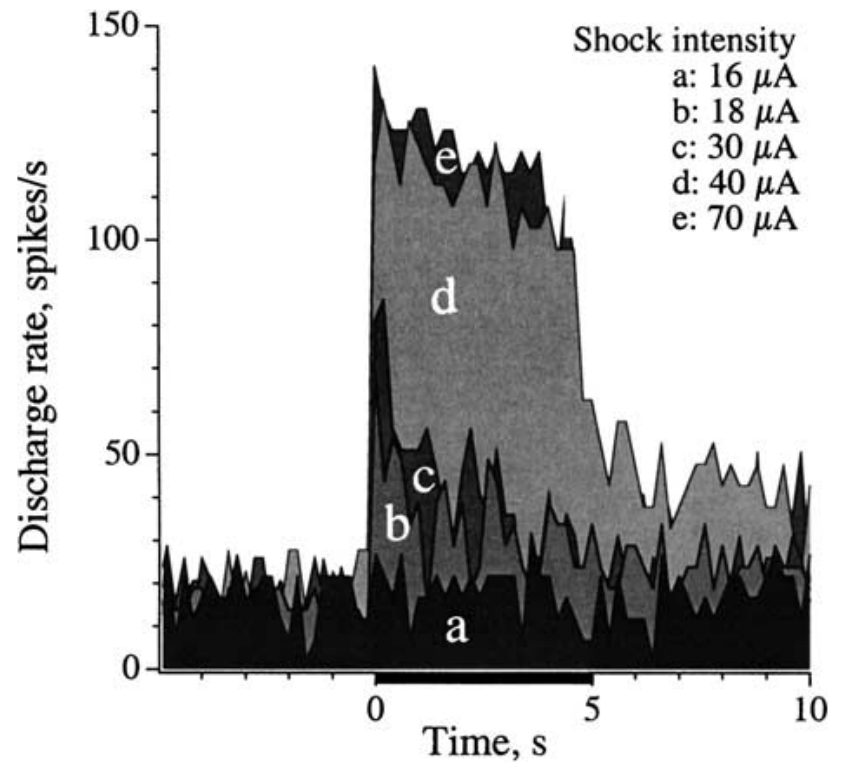

FIG. 3. Responses of a noncalyx $\mathrm{HC}$ unit $\left(\mathrm{Cv}^{*}=0.17\right)$ to electrical stimulation of the contralateral brain stem, 5-s shock trains (horizontal bar), 333 shocks/s. Shock intensity was varied from nearthreshold $(16 \mu \mathrm{A})$ to suprathreshold values (see legend). Responses are plotted from a discharge rate of 17 spikes/s, the average background discharge of the unit.

Guinan 1994), electrical stimulation of efferent pathways in the chinchilla invariably increased the discharge of afferent vestibular units. Single shocks were ineffective, but repetitive shock trains led to clear responses. In the following sections, we describe how the responses were affected by shock intensity, stimulation duration, shock frequency, discharge regularity, and stimulation site.

Shock intensity. As a standard stimulus, we used 5s shock trains at a frequency of 333 shocks/s. The effects of varying shock intensity are illustrated for a noncalyx unit in Figure 3. Stimulation was on the contralateral side. A response was seen at $18 \mu \mathrm{A}$, but not at $16 \mu \mathrm{A}$. Responses increased rapidly between 30 and $40 \mu \mathrm{A}$ to reach a maximum of $\sim 125$ spikes/s.

Thresholds across animals were usually in a range of $10-20 \mu \mathrm{A}$ and were similar for ipsilateral, midline, and contralateral stimulation sites [ANOVA, $F(2$, $23)=0.54, p>0.8]$. As exemplified by Figure 3, responses typically reached near-maximal values at shock strengths $3 \times T$ (threshold). In the following sections, stimulus amplitude was typically set to $30-$ $50 \mu \mathrm{A}$, approximately $3 \times \mathrm{T}$.

In a later section, we compare responses to stimulation of the ipsilateral and contralateral efferent cell groups. The similarity in response thresholds for the two sites effectively rules out the possibility that contralateral responses were due to stimulus spread to the ipsilateral side, some 4-6 $\mathrm{mm}$ away. We routinely found that movement of the stimulating elec- trodes $1 \mathrm{~mm}$ from an optimal location abolished responses to $50-\mu \mathrm{A}$ shocks and raised thresholds to near $100 \mu \mathrm{A}$. (see also Goldberg and Fernández 1980).

Shock-train duration and response kinetics. In previous studies (Goldberg and Fernández 1980; McCue and Guinan 1994), efferent responses were decomposed into fast and slow components, which built up and decayed with time constants $\tau_{F A S T}<0.1 \mathrm{~s}$ and $\tau_{\text {SLOW }}>5 \mathrm{~s}$. Because of the disparity in response kinetics, we can use shock-train duration or, equivalently, the number of shocks to separate the two components (Fig. 4); shock frequency was always 333/s. For short trains (Fig. 4A-D), only a fast component is present: There is a brief increase in discharge that barely outlasts the shock train. Trains lasting a second or more (Fig. 4E-J) generate both fast and slow excitatory responses, with the latter taking $>10 \mathrm{~s}$ of the post-train period to decay.

To estimate the kinetics of the fast response, we plotted the excitatory response as a function of the time in the train, $t$, and fit the points with a simple exponential, $A\left[1-\exp \left(t / \tau_{F A S T}\right)\right]$ (Fig. 5A). We confined the calculation to $t \leq 500 \mathrm{~ms}$ to minimize the responses being contaminated by a slow response. The calculated time constant $( \pm \mathrm{SE})$ for the unit in Figure 5A was $\tau_{F A S T}=84 \pm 6 \mathrm{~ms}$. A similar analysis, done in a second unit, gave a $\tau_{F A S T}=64 \pm 7 \mathrm{~ms}$.

We estimated the kinetics of the slow response from a simple exponential fit of the post-train response decay. To avoid contamination from the fast response, the first second of the post-train period was excluded from the regression. In the example of Figure $5 \mathrm{~B}$, the estimated $\tau_{S L O W}=26 \pm 1.8 \mathrm{~s}$. Regressions done on the responses for train durations of $T=1-32 \mathrm{~s}$ (Fig. 4E-J) gave an average ( \pm SEM) $\tau_{\text {SLOW }}$ of $25.6 \pm 5.8 \mathrm{~s}$. Similar calculations were done in 30 units, in all cases with our standard 5-s shock train. The average $\tau_{S L O W}$ was $25 \pm 4.0 \mathrm{~s}$. A second method of estimating $\tau_{S L O W}$ is illustrated in Figure $5 \mathrm{C}$, where the slow response $(S)$, measured during the post-train period, is plotted versus train duration. Points are fit by a simple exponential function with $\tau_{\text {SLOW }}=2.7 \pm 0.9 \mathrm{~s}$, about 10 times smaller than the time constant of the post-train response decay. In the next section, we use low shock frequencies to evoke a slow response in the absence of a fast response. Under those circumstances, the discrepancy between the buildup and decay of the slow response disappears. This suggests that the concomitant presence of a fast response during the train may affect the buildup of the slow response.

There is an adaptation of the fast response as train duration is prolonged. This is reflected in the rapid termination of the fast response at the end of the train $\left(F_{2}\right)$ being smaller than the abrupt rise at the 


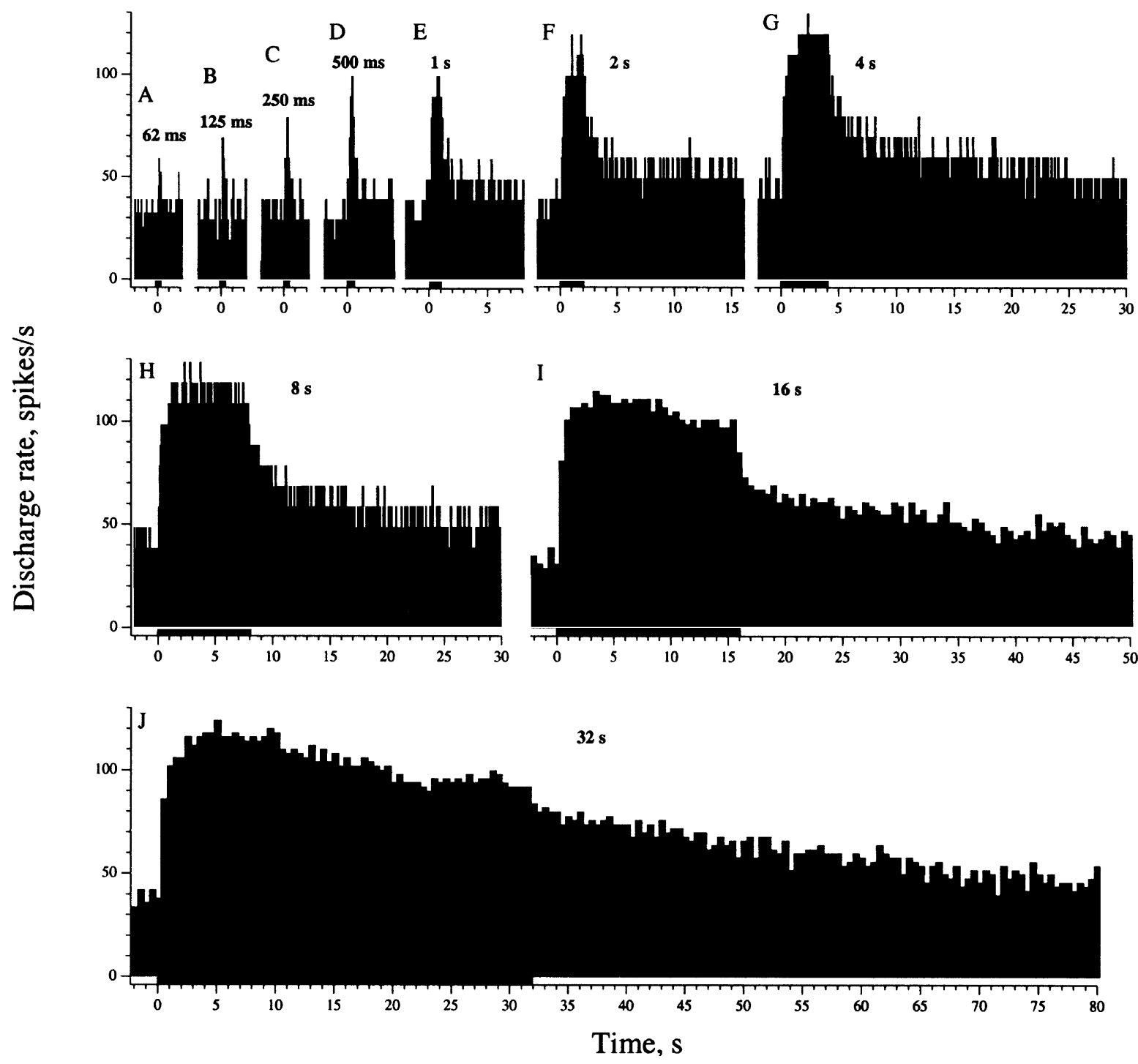

FIG. 4. Shock-train duration distinguished a fast and a slow response component. Responses of a calyx SC unit (Cv* $=0.25)$ to electrical stimulation of the brain-stem midline, 333 shocks/s, $58 \mu \mathrm{A}(3 \mathrm{xT})$. Shock-train duration was varied from $62 \mathrm{~ms}$ to $32 \mathrm{~s}$ (horizontal bars). Histogram for $62 \mathrm{~ms}$, averaged for 3 repetitions; other histograms, one repetition. Bins: $0.1 \mathrm{~s}(62 \mathrm{~ms}-8 \mathrm{~s}), 0.5 \mathrm{~s}$ (16 and $32 \mathrm{~s})$.

beginning of the train $\left(F_{1}\right)$ (Fig. 5B). In Figure 5D, the decline in $F_{2}$ with train duration $(t)$ is fit by an exponential function, $F_{2}(t)=F_{1} \exp (-t / \tau)$, with a time constant $\tau=12.3 \pm 2.3 \mathrm{~s}$. In the sample of 118 canal units, the mean $F_{2} / F_{1}$ ratio for our standard 5-s shock train was $0.45 \pm 0.02$; substituting this value into the exponential equation gives a time constant of $5.8 \pm 0.04 \mathrm{~s}$.

To study adaptation of the slow response, we modified a previously published paradigm (McCue and Guinan 1994) (Fig. 6). Brief (0.5 s) shock trains at a frequency of $333 / \mathrm{s}$ were delivered every $1.5 \mathrm{~s}$. A total of 50 trains were presented. Average rates were calculated during each train $\left(T_{1}\right)$ and in the $0.5-\mathrm{s}$ period immediately preceding the train $\left(T_{0}\right)$. Because of the short intertrain interval, the slow response increases during successive trains with the result that there is a gradual increase in the $T_{0}$ and $T_{1}$ rates as the paradigm continues. The specific measure of the slow response at time $t$ is the difference in $T_{0}$ rates at $t$ and at the beginning of the paradigm, $t=0$. In addition, a fast response is measured as the difference in rates between $T_{1}$ and the immediately preceding $T_{0}$ (shaded areas in Fig. 6). Adaptation of the slow response could be seen as a decline in the $T_{0}$ rate after it reaches a maximum, while adaptation of the fast response was measured as a decline in the $T_{1}-T_{0}$ differential rate from its maximum near $t=0$. In Figure 6A, adaptation of the slow response is not seen. Rather, the $T_{0}$ rate continues to increase throughout the nearly $75 \mathrm{~s}$ of the paradigm. Even when such adaptation was present (Fig. 6B), the decline in the $T_{0}$ rate was usually small and always incomplete, seldom exceeding $50 \%$. Similarly, the time- 


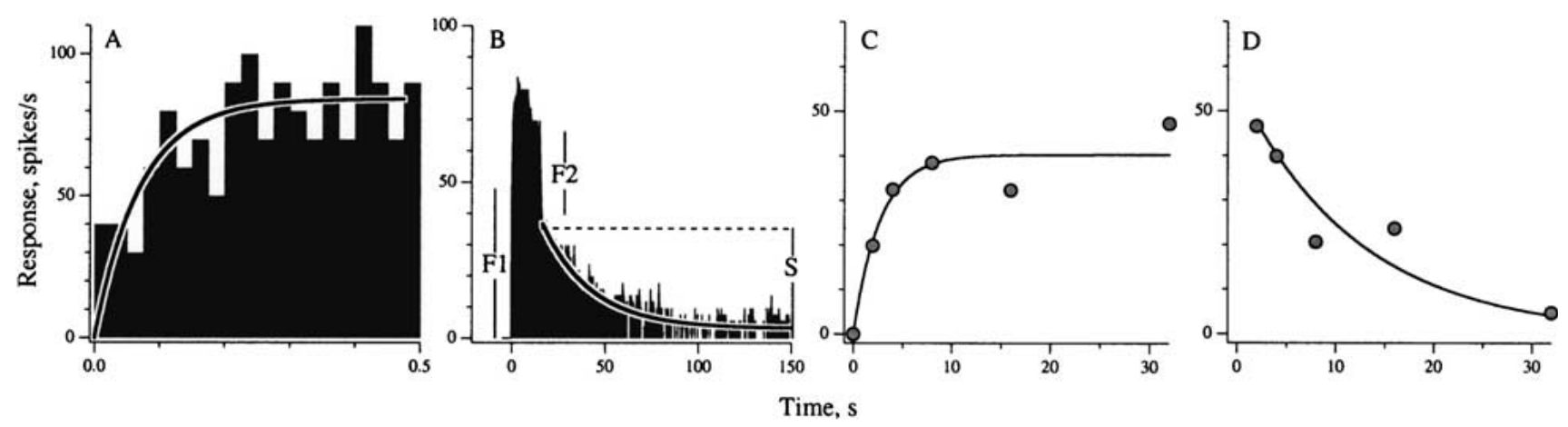

FIG 5. Kinetics of fast and slow response components. Same calyx unit as in Fig. 4. A Rate increase during the first $500 \mathrm{~ms}$ of the shock train illustrates the buildup of the fast response, which is fit by an exponential with a 80-ms time constant. An average of 7 repetitions. B Response to 16-s shock train. The decay of the slow response, starting $1 \mathrm{~s}$ into the post-train period, is fit by an exponential. The difference in the abrupt changes in rate at the beginning $\left(F_{1}\right)$ and end $\left(F_{2}\right)$ of the shock train reflects the adaptation of the fast response. The amplitude of the slow response $(S)$ is estimated by the extrapo- lation of the exponential fit back to the start of the post-train period. $F_{1}$ is the response averaged during the first $0.5 \mathrm{~s}$ of the shock train and $F_{2}$ is the difference in rates during the last $1 \mathrm{~s}$ of the shock train and the slow response amplitude $(S)$. C $S$ is plotted versus the duration of the preceding shock train and fit by a simple exponential with a time constant of $2.7 \pm 0.9 \mathrm{~s}$. D $F_{2}$ is plotted as a function of train duration and fit by an exponential with a time constant of $12.3 \pm 2.3 \mathrm{~s}$.

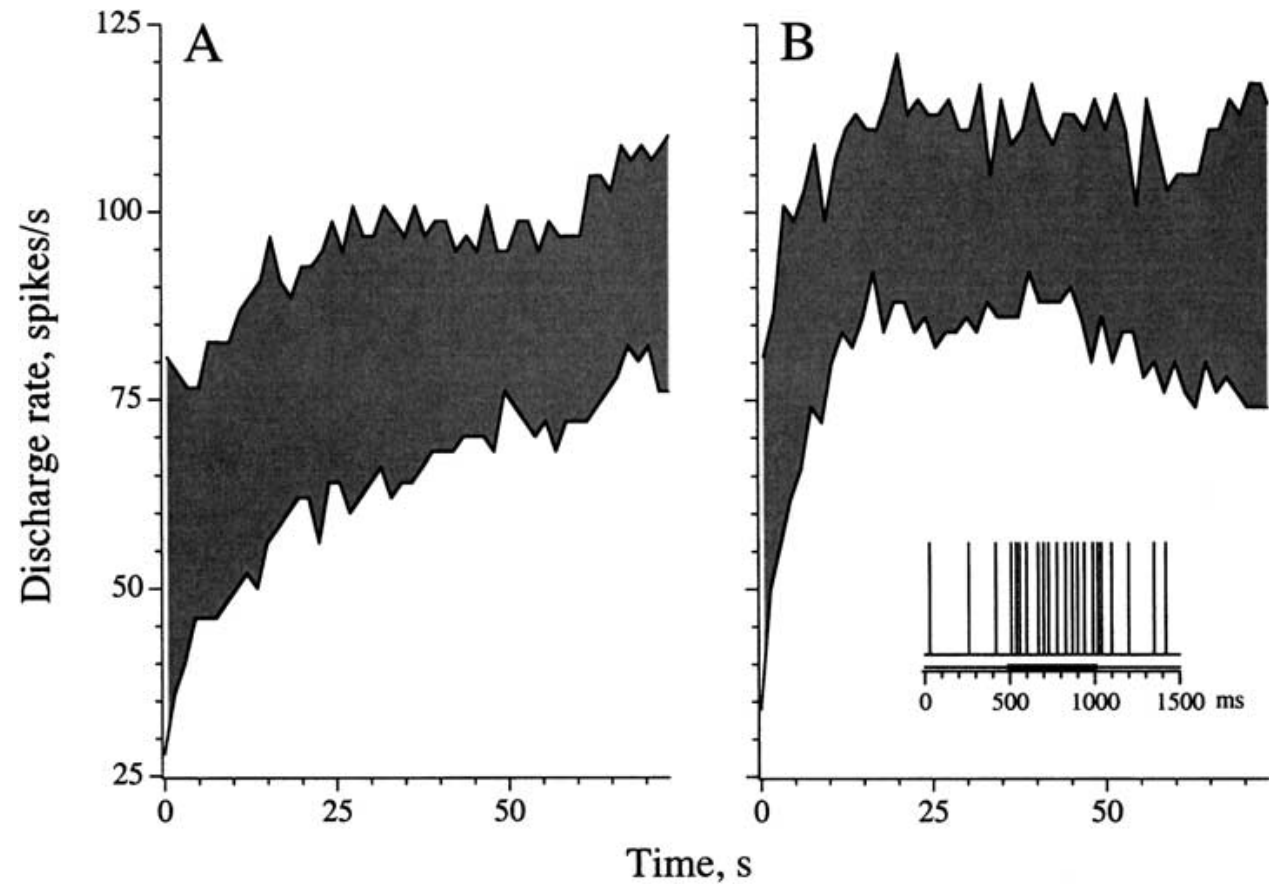

FIG 6. Adaptation of slow and fast response components. Shock trains, 0.5-s duration, 333 shocks/ $\mathrm{s}$ are repeated every $1.5 \mathrm{~s}$. There are a total of 50 trains. Rates are calculated during each train $\left(T_{1}\right.$, dark bar in inset to $\left.\mathbf{B}\right)$ and in the $0.5 \mathrm{~s}$ immediately preceding period $\left(T_{0}\right)$. The slow response builds up with successive trains. The fast response is measured as the difference in rates between $T_{1}$ and the immediately preceding $T_{0}$ (shaded areas). A A noncalyx $\mathrm{HC}$ unit $\left(\mathrm{Cv}^{*}=0.16\right)$, ipsilateral stimulation. The slow response continues to increase during the paradigm, while the fast response declines from 52 to 34 spikes/s. B A calyx SC unit $\left(\mathrm{CV}^{*}=0.25\right)$, midline stimulation. The slow response declines from 57 to 39 spikes/s; the fast response declines from 47 to 40 spikes/s. dependent decline in the fast response was usually small; in Figure $6 \mathrm{~A}$, the decline was $\sim 35 \%$, while in Figure $6 \mathrm{~B}$, it was $\sim 15 \%$.

Of the 31 units tested with the McCue-Guinan (1994) paradigm, we selected 15, which showed both fast and slow responses. The peak slow response averaged $15.0 \pm 3.3$ spikes/s (range: $4.3-42$ spikes/s); the peak fast response had a mean of $14.4 \pm 3.8$ spikes/s (range: 0.8-42 spikes/s). Fast and slow response amplitudes were correlated $(r=0.88, p<$ $0.001)$. Adaptation of the slow response resulted in an average decline of $24.0 \pm 4.2 \%$ in the $T_{0}$ rate from its peak value; adaptation of the fast response led to a mean decline of $27.4 \pm 7.7 \%$ in the $T_{1}-T_{0}$ differential rate. Adaptation indices for the two response components were not significantly correlated $(r=-0.26, \mathrm{p}>0.05)$.

Shock frequency was varied while the number of shocks was held constant. Results were obtained in 12 units, including the example in Figure 7. Fast responses, marked by an abrupt rate transition at the beginning of the shock train, were most conspicuous at $333 / \mathrm{s}$ (Fig. 7 A) but were barely discernible at 100/s (Fig. 7C) and 50/s (Fig. 7D). We used the $F_{1} / S$ 

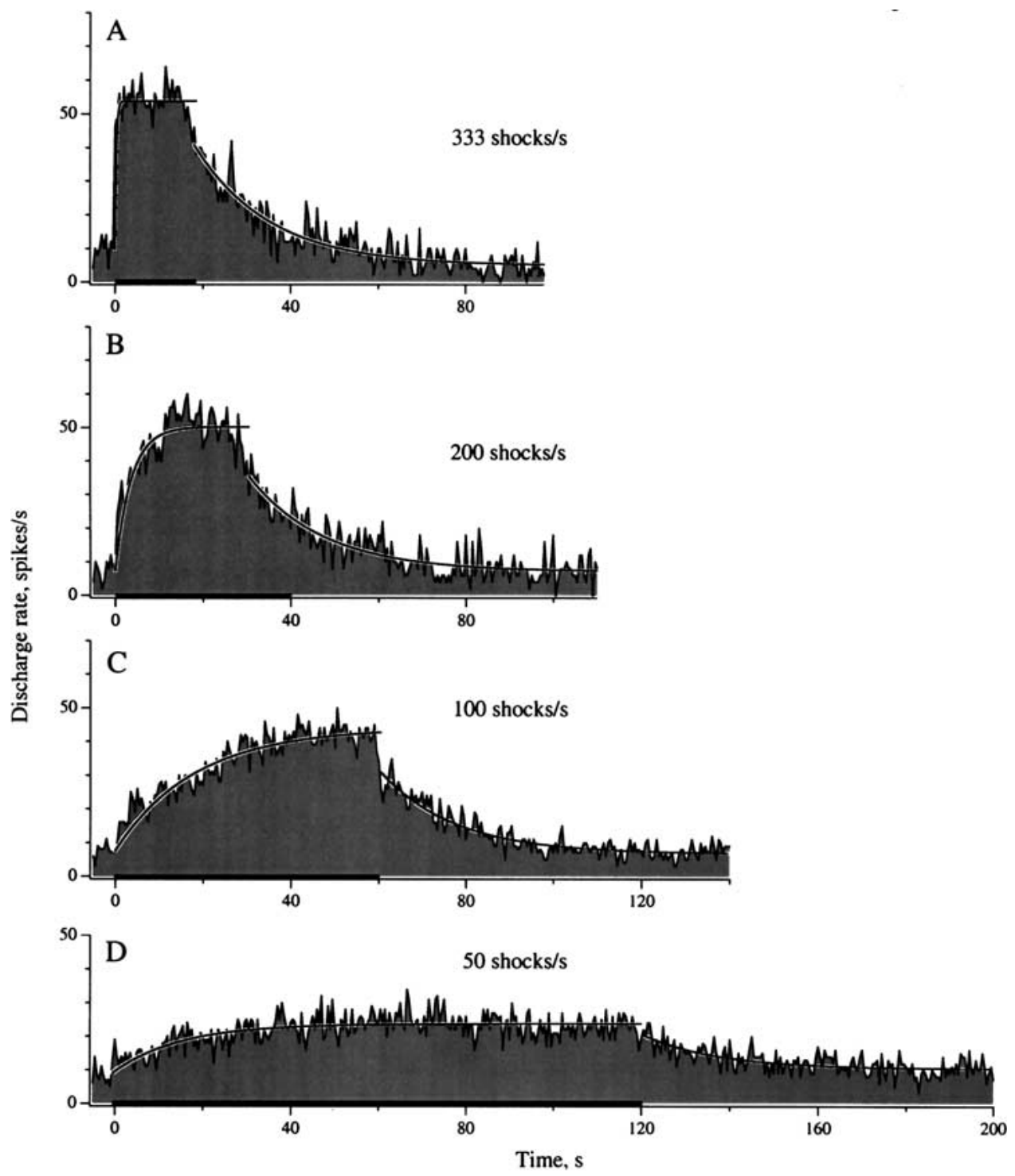

FIG. 7. Fast and slow responses behave differently as shock frequency changes. Same unit as in Fig. 4. Shock frequencies: 333 (A), $200(\mathbf{B}), 100(\mathbf{C})$, and 50/s (D); train duration increases so that the number of shocks remains at 6000. A fast response is seen only at the beginning of the higher-frequency shock train. A slow response is seen in the post-train period at all frequencies and is also observed uncontaminated by a fast response during low-frequency shock trains. Separate simple exponentials are fit to the per-train response buildup and post-train response decay.

ratio, as defined in the legend to Figure $5 \mathrm{~B}$, to quantify results. $F_{1}$ and $S$ components were approximately equal in size at 333/s (Fig. 7A) with the $F_{1} / S$ ratio for the 12 units averaging $0.96 \pm 0.11$. As shock frequency declined, $F_{1}$ declined more rapidly than $S$, so that the population $F_{1} / S$ was $0.52 \pm 0.11$ at $200 / \mathrm{s}$ and $0.14 \pm 0.10$ at $100 / \mathrm{s}$.

Fast responses were conspicuous only at high shock frequencies. This has a bearing on the buildup of the response during the shock train. The buildup could be fast at high rates, in part reflecting the presence of a fast response. In addition, as we have already seen (Fig. 5C), there may be an interaction between the fast and slow responses. As shock frequency was lowered and the slow response began to predominate, the per-stimulus time constant lengthened and approached the post-stimulus time constant. For the unit in Figure 7, per-stimulus exponential time constants were $0.3 \mathrm{~s}(333 / \mathrm{s}), 4.1 \mathrm{~s}$
$(200 / \mathrm{s}), 17.7 \mathrm{~s}(100 / \mathrm{s})$, and $18.2 \mathrm{~s}(50 / \mathrm{s})$. The last two values were similar to post-train values, which averaged $17.0 \mathrm{~s}$ for the four panels of Figure 7. For the sample of 12 units, the average per-train time constant varied from $0.9 \pm 0.2 \mathrm{~s}(333 / \mathrm{s})$ to $29.2 \pm$ $6.8 \mathrm{~s}(50 / \mathrm{s})$ compared with a post-train average of $25.5 \pm 2.9 \mathrm{~s}$.

Based on a simple linear model (Goldberg and Fernández 1980), the buildup and decay of the slow response should have the same kinetics. Hence, the similarity between the per-train and post-train time constants at the lower shock frequencies is consistent with the conclusion that per-train responses become dominated by slow components. During stimulation at 100 (Fig. 7C) or 50 shocks/s (Fig. 7D), there is little response decline even though the shock trains last $60-120 \mathrm{~s}$. This provides additional evidence that there is little adaptation of the slow response. In contrast, the $F_{2} / F_{1}$ ratios included in Table 1 indicate 


\section{TABLE 1}

Efferent response indices versus unit group, stimulation site, and discharge regularity ${ }^{a}$

\begin{tabular}{|c|c|c|c|c|c|c|c|}
\hline Unit group & $n$ & $C v^{*}$ & $F_{1}$ (spikes/s) & $F_{2}$ (spikes/s) & S (spikes/s) & $F_{2} / F_{1}$ & $F_{1} / S$ \\
\hline \multicolumn{8}{|l|}{ Ipsilateral } \\
\hline \multicolumn{8}{|l|}{ Noncalyx } \\
\hline Regular & 22 & 0.035 & $8.1 \pm 1.1$ & $3.6 \pm 0.6$ & $9.7 \pm 1.7$ & $0.45 \pm 0.06$ & $0.8 \pm 0.2$ \\
\hline Nonregular & 15 & 0.15 & $37.7 \pm 6.2$ & $16.0 \pm 3.6$ & $23.6 \pm 4.5$ & $0.42 \pm 0.04$ & $1.6 \pm 0.6$ \\
\hline Calyx & 14 & 0.37 & $59.2 \pm 10.4$ & $30.8 \pm 6.2$ & $24.0 \pm 6.7$ & $0.52 \pm 0.05$ & $2.5 \pm 0.5$ \\
\hline \multicolumn{8}{|c|}{ Contralateral and midline } \\
\hline \multicolumn{8}{|c|}{ Noncalyx } \\
\hline Regular & 24 & 0.033 & $7.1 \pm 0.8$ & $1.7 \pm 0.3$ & $6.7 \pm 0.7$ & $0.23 \pm 0.04$ & $1.0 \pm 0.2$ \\
\hline Nonregular & 18 & 0.19 & $30.3 \pm 8.8$ & $11.5 \pm 3.4$ & $18.7 \pm 4.0$ & $0.38 \pm 0.05$ & $1.6 \pm 0.4$ \\
\hline Calyx & 25 & 0.37 & $35.3 \pm 4.7$ & $17.0 \pm 2.8$ & $19.3 \pm 2.2$ & $0.48 \pm 0.04$ & $1.8 \pm 0.3$ \\
\hline \multicolumn{8}{|l|}{ All sites } \\
\hline \multicolumn{8}{|l|}{ Noncalyx } \\
\hline Regular & 46 & 0.034 & $7.6 \pm 0.7$ & $2.6 \pm 0.4$ & $8.2 \pm 0.9$ & $0.34 \pm 0.04$ & $0.9 \pm 0.1$ \\
\hline Nonregular & 33 & 0.17 & $33.7 \pm 5.5$ & $13.5 \pm 2.4$ & $20.9 \pm 3.0$ & $0.40 \pm 0.04$ & $1.6 \pm 0.4$ \\
\hline Calyx & 39 & 0.37 & $43.9 \pm 5.1$ & $21.9 \pm 3.0$ & $21.0 \pm 2.8$ & $0.50 \pm 0.03$ & $2.1 \pm 0.3$ \\
\hline
\end{tabular}

${ }^{a} n$-number of units. Other entries are mean \pm SE. The values for $F_{2} / F_{1}$ and $F_{1} / S$ were calculated from the means of the individual indices.

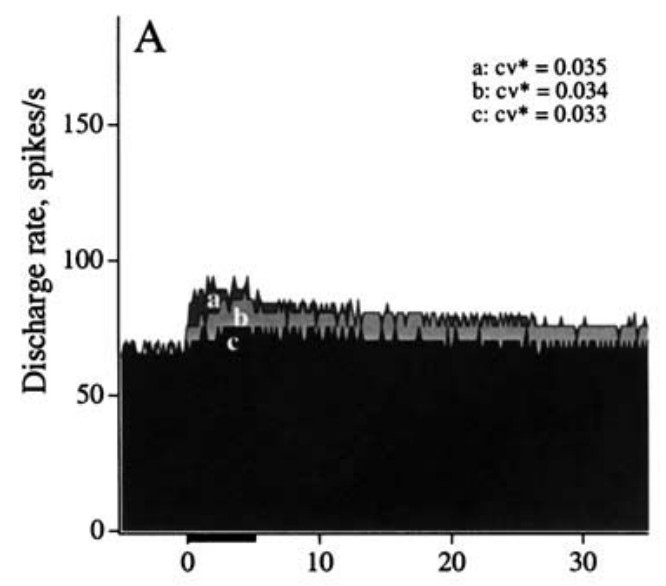

Time, s

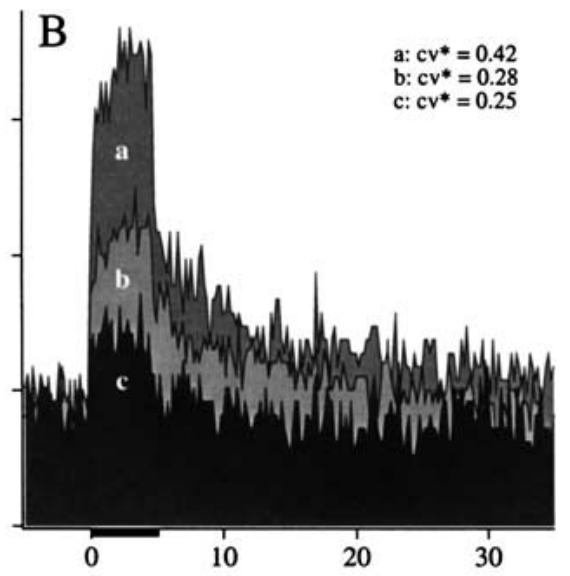

FIG. 8. Efferent responses are larger in irregular, as compared to regular units. Comparison of responses in three regular (A) and three irregular units (B). Ipsilateral stimulation, 5-s shock trains, 333/s in all cases. For each panel, units had similar background discharges: A 66.8 (a), 65.4 (b), 65.8 (c) spikes/s and B 41.2 (a), 49.8 (b), and 44.0 (c) spikes/s. All units were HC except $\mathrm{Bb}$, an SC unit. Calyx units are $\mathrm{Ba}$ and $\mathrm{Bc}$. Responses are plotted from an averaged discharge rate of 66 (A) and 45 spikes/s (B). that the fast response declines by $50 \%$ or more during 5-s trains.

Discharge regularity, stimulation site, calyx vs. noncalyx units. In the squirrel monkey, the sizes of efferent responses were related to discharge regularity (Goldberg and Fernández 1980). The same was true in the present study. Responses to ipsilateral stimulation are compared for regular (Fig. 8A) and irregular units (Fig. 8B). Overall responses are much larger in irregular units. In addition, in most irregular units (Fig. 8Ba, b) there is a conspicuous fast response $\left(F_{1}\right)$ at the beginning of the shock train and an abrupt decline in rate $\left(F_{2}\right)$ at train termination. For many regular units (Fig. 8Ab, c), the buildup and decline of responses are predominantly slow. There are exceptions to these rules. For example, a regular unit (Fig. 8Aa) shows an abrupt rate change at train start, though not at train end. Similar differences in both response magnitude and response form were seen when efferent responses were compared for regular and irregular units during ipsilateral (Fig. 9 A), midline (Fig. 9B), or contralateral stimulation (Fig. 9C). Based on the anatomical results of Purcell and Perachio (1997b), we had supposed that irregular units would show only small responses to midline or contralateral stimulation. The responses of the irregular units in Figure 9B, C contradict the conjecture. Large responses of irregular afferents to midline or contralateral stimulation were common (Figs. 3, 4, $6 B)$.

The relation between discharge regularity $\left(\mathrm{Cv}^{*}\right)$ and efferent response is plotted versus $\mathrm{cv}^{*}$ when stimulation was on the ipsilateral (Fig. 10A) or contralateral sides (Fig. 10G) or in the midline 

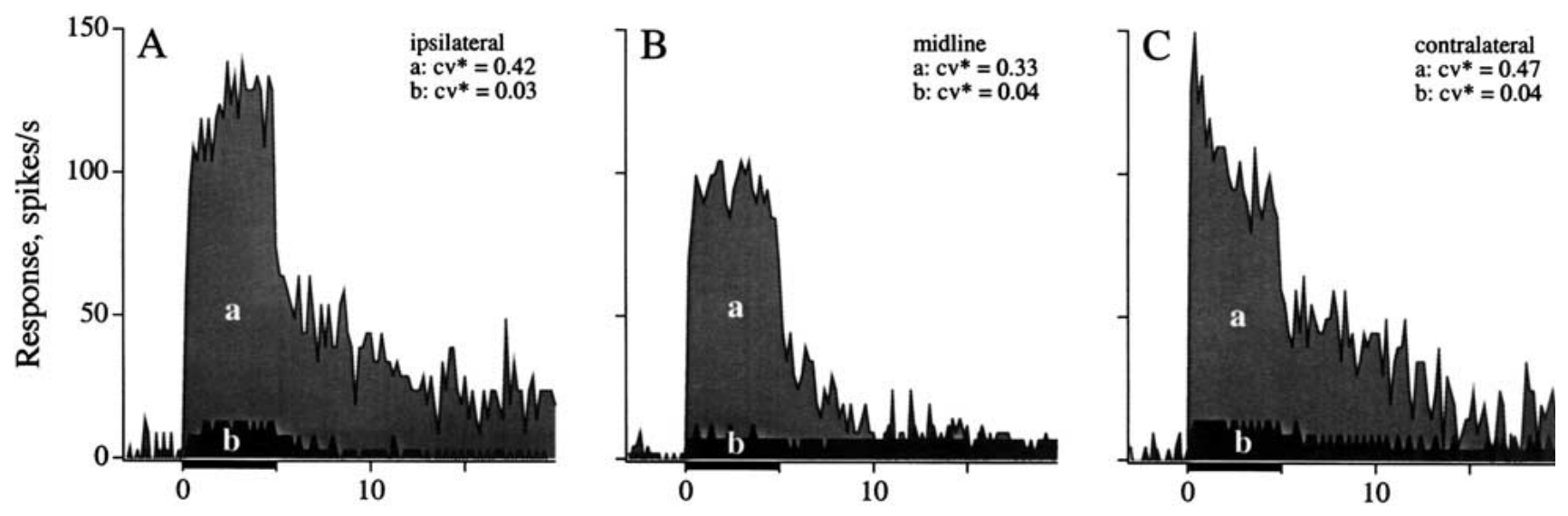

Time, $s$

FIG. 9. Efferent responses are similar for ipsilateral (A), midline (B), and contralateral (C) stimulation. Each panel shows responses for an irregular (a) and a regular unit (b). Irregular afferents were calyx units except Ca.
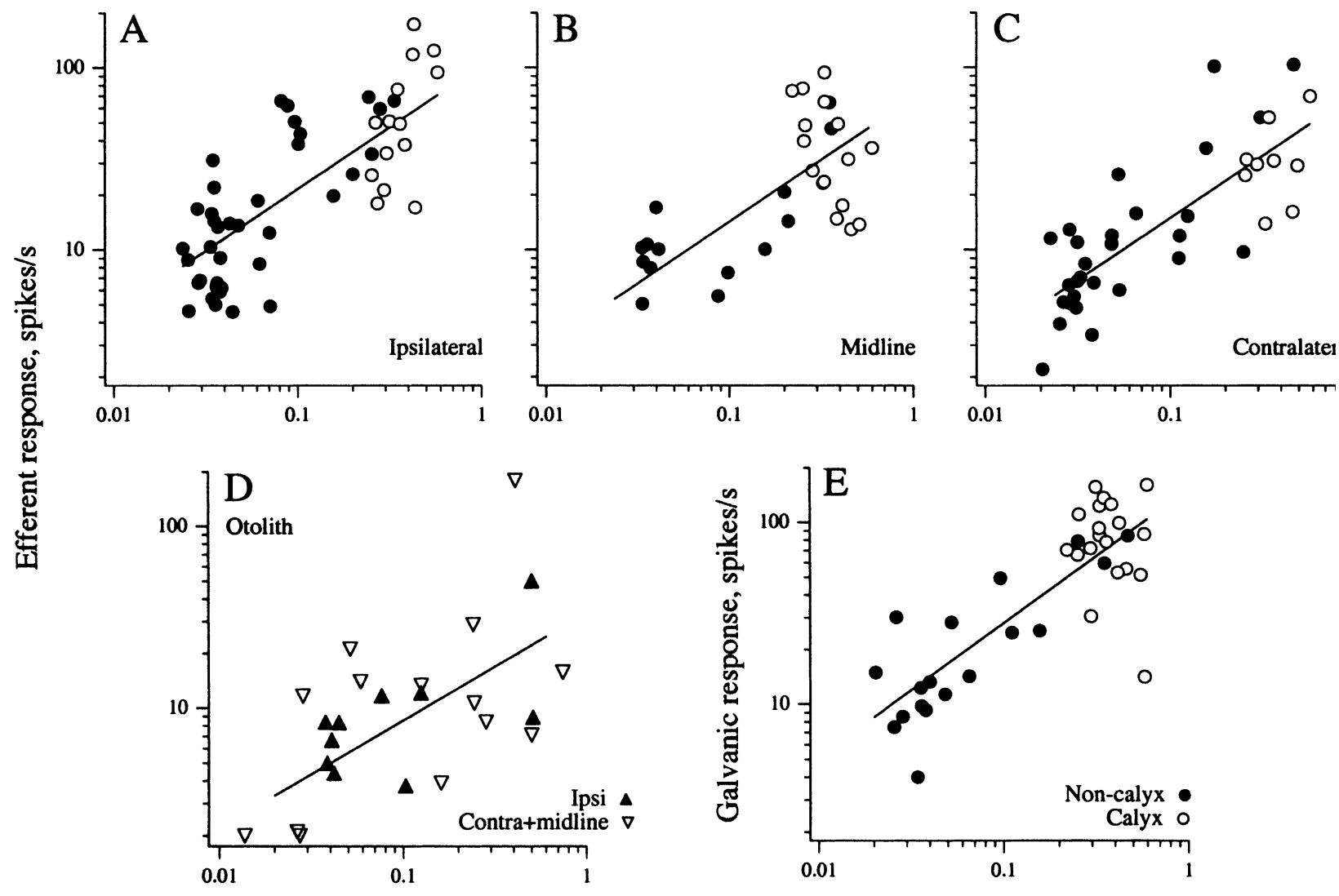

Coefficient of variation, $\mathrm{cv}^{*}$

FIG. 10. Efferent response magnitudes parallel responses to galvanic currents. For canal afferents responses averaged over a 5-s efferent shock train are plotted against a normalized coefficient of variation $\left(\mathrm{Cv}^{*}\right)$ for ipsilateral $(\mathbf{A})$, midline $(\mathbf{B})$, and contralateral $(\mathbf{C})$ efferent stimulation. D Efferent response magnitude versus $\mathrm{Cv}^{*}$ for otolith afferents. Responses to ipsilateral stimulation are indicated by

(Fig. 10B). Separate symbols are used to denote unit type (calyx or noncalyx). In all cases, responses were to 5-s shock trains, 333 shocks/s. Similar relations filled triangles; responses to midline and contralateral stimulation are indicated by inverted open triangles. A-D 333/s, 40-70 $\mu$ A shocks. E Relation between the response to $50-\mu \mathrm{A}$ galvanic currents aid $\mathrm{Cv}^{*}$. Straight lines are power-law fits; calyx and noncalyx units indicated by unfilled $(\bigcirc)$ and filled symbols $(-)$, respectively. Slopes of the fitted lines in A-D and $\mathbf{E}$ are similar.

were observed for all three stimulation sites. An analysis of covariance (ANCOVA) was used to investigate whether the relation between response magni- 
$\mathbf{A}$

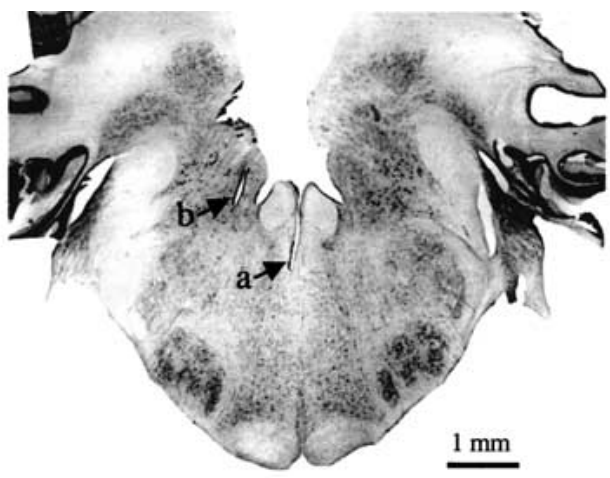

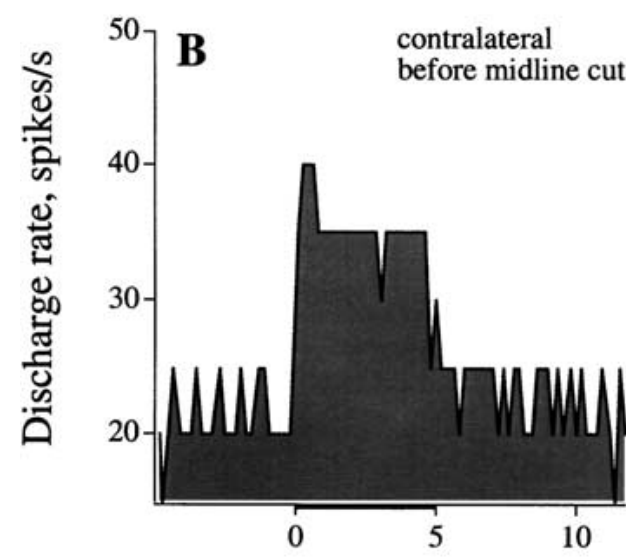

FIG. 11. Midline lesion abolishes response to contralateral efferent stimulation. Recording from a noncalyx, $\mathrm{SC}$ unit $\left(\mathrm{CV}^{*}=0.08\right)$; efferent stimulation, 333/s, $5 \mathrm{~s}, 50 \mu \mathrm{A}$. A Cross-section of brain stem shows midline lesion (a) and electrolytic mark of ipsilateral stimu-

tude and $\mathrm{Cv}^{*}$ was influenced by stimulation site or unit type. Unit type had no effect $(p>0.6)$, but stimulation site had a significant influence $(p<0.01)$. Smaller responses were obtained with midline or contralateral stimulation than with ipsilateral stimulation $(p<0.02$ in both cases). Exponents from power-law regressions-response $=\mathrm{a} \cdot \mathrm{cv}^{* b}$-were not significantly different for the three relations and provided a pooled value, $b=0.68 \pm 0.05$. The multiplicative constant $a$ was 1.5 times higher for ipsilateral stimulation (102.3 $\pm 9.0 \mathrm{spikes} / \mathrm{s})$ than for midline or contralateral stimulation $(67.6 \pm 8.1$ and $70.8 \pm 7.0$ spikes/s, respectively).

We were also interested in whether the shape, as well as the magnitude, of the efferent response was influenced by discharge regularity, unit type, and stimulation site. To this end, we tabulated the response indices $F_{1}, F_{2}$, and $S$, as well as the ratios $F_{2} / F_{1}$ and $F_{1} / S$ for the three unit categories (Table 1 ). ANCOVAs indicated that the differences between groups reflected their $\mathrm{Cv}^{*} \mathrm{~s}$ rather than unit type per $s e$. Stated another way, differences between calyx and noncalyx units can be entirely explained by the former units being the most irregular units in the sam- lation site (b). Response to contralateral stimulation (B) is abolished after midline lesion $(\mathbf{C})$. The stimulating array was then moved to ipsilateral side and a large response was obtained (D).

ple. The same ANCOVAs indicated that there were small differences with stimulation site for some of the indices, but a perusal of the table indicated that the differences did not obscure trends based on $\mathrm{Cv}^{*}$. From the pooled data at the bottom of Table 1 (All sites), we see that $F_{1}$ grew with $\mathrm{cv}^{*}$ both absolutely and relative to $\mathrm{S}$. There was a more than tenfold variation in $\mathrm{Cv}^{*}$ between noncalyx regular and calyx units. $F_{1}$ and $S$ were nearly equal in regular units, but $F_{1}$ was twice as large as $S$ in calyx units. Reflecting the differential growth of $F_{1}$, a pooled power-law regression between the $F_{1} / S$ ratio and $\mathrm{cv}^{*}$ gave a positive, statistically significant exponent, $b=0.35 \pm 0.07(p \ll$ $0.001)$. The $F_{2} / F_{1}$ ratio is a measure of fast-response adaptation during the 5-s shock train; the smaller the ratio, the greater the adaptation. The exponent from a power-law regression between $F_{2} / F_{1}$ and $\mathrm{cv}^{*}$, $b=0.17 \pm 0.05$, was significant $(p<0.01)$ and consistent with the 1.5 -fold decrease in the $F_{2} / F_{1}$ ratio between calyx units and noncalyx regular units. It would thus appear that fast adaptation is more conspicuous in regular units.

Regular and irregular fibers differ in their efferent responses. To investigate a possible explanation for 
the difference, we studied responses to galvanic currents delivered by way of the round window. Responses, averaged for a 5-s, 50- $\mu$ A cathodal current, are plotted against $\mathrm{Cv}^{*}$ in Figure 10E. As had been found previously (Goldberg et al. 1984; Baird et al. 1988), galvanic sensitivity was related to $\mathrm{Cv}^{*}$ by a power law. The exponent, $b=0.74 \pm 0.09$, was nearly identical to the pooled exponent, $b=0.68 \pm 0.05$, for the relations between efferent response magnitude and $\mathrm{Cv}^{*}$ (Fig. 10A-C). The similarity in exponents suggests that the same mechanisms underlie the two relations with $\mathrm{Cv}^{*}$. Galvanic sensitivity reflects the sensitivity of the spike encoder in the afferent terminal (Goldberg et al. 1984; Smith and Goldberg 1986) and the same may be true for efferent-response magnitude.

Otolith afferents. Efferent responses of otolith fibers resembled those of canal fibers in being exclusively excitatory, in consisting of fast and slow components, and in being larger in irregular fibers. Figure 10D plots efferent response magnitude versus $\mathrm{Cv}^{*}$ for the otolith population. A power-law regression combined for all three sites gave an exponent, $b=0.59 \pm 0.16$, statistically indistinguishable from the exponent for canal fibers. The multiplicative constant, $a=33.3 \pm 14.1$ spikes/s, was 2-3 times smaller than the corresponding canal values. Separate power-law regressions comparing ipsilateral with contralateral plus midline stimulation were similar.

No attempt was made in this study to distinguish calyx from noncalyx otolith units because the former, while being the most irregularly discharging units supplying otolith organs, do not have distinctively low gains (Goldberg et al. 1990b). Irregular otolith units do not seem to form distinct groups in Figure 10D, suggesting that the efferent responses of calyx otolith units are not distinctive.

Effects of midline lesions on contralateral efferent responses. Contralateral stimulation leads to large efferent responses in irregular units. This would seem contradictory to the conclusion that contralateral efferents do not project to the central zone of the cristae (Purcell and Perachio 1997b), where irregular afferents terminate (Baird et al. 1988). The contradiction would be explained were the responses to contralateral stimulation not the result of direct activation of contralateral efferents.

A test of the direct involvement of contralateral efferents is provided by their crossing the midline just below the IVth ventricle (Lysakowski and Singer 2000). We determined whether contralateral responses survived midline lesions that may sever crossing efferent axons. Results from one such experiment are shown in Figure 11. The contralateral response seen in a noncalyx unit (Fig. 11B) was abolished by a midline section to a depth of $1 \mathrm{~mm}$
(Fig. 11C). Efferent responses returned in the unit when the stimulating array was moved to the ipsilateral side (Fig. 11D). Effects of superficial midline lesions on the contralateral responses of individual units were tested in two other animals. In each animal, contralateral responses were monitored in an individual unit before and after a midline lesion. Responses were abolished in one animal and reduced by $>80 \%$ in the other animal.

\section{DISCUSSION}

The present study demonstrates that responses to electrical stimulation of efferent pathways in the chinchilla resemble those previously obtained in the squirrel monkey (Goldberg and Fernández 1980) and the cat (McCue and Guinan 1994). Only excitatory responses are seen and consist of fast and slow response components. Responses of irregular units are larger and have more conspicuous fast components than do those of regular units. The relations between response magnitude and discharge regularity $\left(\mathrm{cv}^{*}\right)$ are statistically indistinguishable for calyx and noncalyx units. Except for a small difference in magnitude, similar responses are obtained with stimulation on the ipsilateral or contralateral side and this is true for regular and for irregular canal units. Qualitatively similar efferent responses were seen in canal and otolith afferents though the responses were smaller in otolith fibers.

Based on the similarity of the results with those from other mammals, we conclude that the chinchilla provides a suitable model for the study of efferent actions. One reservation is that we have not adequately studied the effects of efferent stimulation on the afferent responses to sensory inputs in the chinchilla. In the squirrel monkey (Goldberg and Fernández 1980) and toadfish (Boyle and Highstein 1990), efferent activation reduces the responses to head rotations, consistent with efferents exerting an excitatory action.

\section{Excitatory nature of the responses}

As in the squirrel monkey (Goldberg and Fernández 1980) and cat (McCue and Guinan 1994), efferent responses in the chinchilla were invariably excitatory. We now suspect that the few inhibitory responses described in the squirrel monkey (Goldberg and Fernández 1980) were not legitimate but rather were the result of misidentifying antidromically activated spikes as shock artifacts. In the few reports implying that efferent actions are inhibitory in mammals (Sala 1965; Kashii et al. 1987) it is unclear that efferent pathways were stimulated or that recordings were made from peripheral vestibular neurons. 
When it was first reported (Goldberg and Fernández 1980), the fact that efferents exerted an excitatory action in the mammalian vestibular labyrinth seemed surprising since other studies had shown that efferent actions in auditory and vibratory organs were inhibitory (Wiederhold and Kiang 1970; Flock and Russell 1973, 1976; Furukawa 1981; Ashmore and Russell 1982; Art et al. 1984). In retrospect, the challenge was to explain how an efferent action based on ionotropic, cholinergic neurotransmission (Bobbin and Konishi 1971, 1974) could give rise to inhibition. The synaptic basis of efferent inhibition has now been worked out (Fuchs and Murrow 1992a, b). Inhibition takes place in hair cells and is the result of the activation of $\alpha 9 / 10$ nicotinic channels (Elgoyhen et al. 2001), whose opening allows the entry of $\mathrm{Ca}^{2+}$ ions (Weisstaub et al. 2000) and the activation of calcium-activated $\mathrm{K}^{+}$channels of the SK variety (Oliver et al. 2000). Outward currents through the SK channel hyperpolarize the hair cell and inhibit neurotransmitter release.

To date, efferent excitation has been confined to vestibular organs. Excitation, revealed by an increase in afferent discharge, is seen in a fraction of irregularly discharging afferents in the frog (Rossi et al. 1980, 1994; Bernard et al. 1985; Sugai et al. 1991) and in calyx-bearing afferents in the turtle (Brichta and Goldberg 2000). It is the predominant action in the horizontal crista of the toadfish (Boyle and Highstein 1990; Boyle et al. 1991) and in the entire vestibular labyrinth of mammals (Goldberg and Fernández 1980). The basis of the excitation may be heterogeneous. In the frog, excitation is associated with an increase in afferent quantal neurotransmission (Rossi et al. 1980, 1994; Bernard et al. 1985; Sugai et al. 1991), which implies that the action is presynaptic onto hair cells. There is some evidence that receptors other than $\alpha 9 / 10$, either nicotinic (Bernard et al. 1985) or purinergic (Rossi et al. 1994), are involved. Another possibility is raised by the observation that efferent inhibition can be converted to excitation by agents that block the SK channel and uncouple it from the preceding $\alpha 9 / 10$ action (Holt et al. 2003).

A second source of efferent excitation may arise postsynaptically. There are efferent endings on calyx and other afferent terminals (Smith and Rasmussen 1968; Iurato et al. 1972; Lysakowski 1996; Lysakowski and Goldberg 1997). Recordings from calyx-bearing afferents in turtles reveal that efferent excitation is the result of an EPSP that is blocked by nicotinic antagonists (Holt et al. 2003). The same study implies that there is a postsynaptic excitation of bouton afferents, which can be masked by the presynaptic inhibition of hair cells. Most afferents in mammals receive afferent inputs from type II hair cells (Fer- nández et al. 1988, 1990, 1995). This is obviously the case for bouton and dimorphic afferents, but even the calyx terminals innervating type I hair cells can be contacted on their outer faces by ribbon synapses from type II hair cells (Lysakowski and Goldberg 1997). Type II hair cells receive a conspicuous efferent innervation (Smith and Rasmussen 1968; Wersall and Bagger-Sjöbäck 1974; Lysakowski 1996; Lysakowski and Goldberg 1997). Inhibition is not seen in mammalian afferents, even those receiving type II inputs. This suggests one of two possibilities: (1) there is a presynaptic efferent inhibition of hair cells that is outweighed by the postsynaptic excitation of calyx endings and other afferent processes, or (2) the presynaptic action is excitatory. Concerning the latter possibility, a presynaptic excitatory action might be mediated by a novel receptor as is suggested in the frog (Rossi et al. 1980, 1994; Bernard et al. 1985; Sugai et al. 1991). As an alternative, the excitation could result from an $\alpha 9 / 10$-mediated excitation that is not completely checked by an activation of SK channels.

\section{Efferent actions, discharge regularity, and neuroepithelial organization}

As was demonstrated previously (Goldberg and Fernández 1980) and confirmed in the present study, efferent excitatory actions in mammals are much larger in irregular, as compared with regular, afferents. A strong relation between efferent responses and discharge regularity is seen for both canal and otolith fibers. There are regional differences in the afferent innervation patterns, with irregular afferents innervating the central region of each crista and the striola of the utricular macula, while regular afferents are found in peripheral (extrastriolar) regions (Baird et al. 1988; Goldberg et al. 1990b). The differences in efferent responses' magnitudes cannot be explained by regional differences in the density of efferent innervation, which is heaviest in the peripheral zone (Nomura et al. 1965; Lysakowski and Goldberg 1997) and parallels the density of hair cells (Lindeman 1969; Fernández et al. 1995; Lysakowski and Goldberg 1997) and afferent fibers (Fernández et al. 1988, 1990, 1995). Quantitative electron microscopy indicates that the number of efferent boutons supplying individual type II hair cells and individual calyx endings is relatively uniform throughout the crista (Lysakowski and Goldberg 1997). Regional differences in efferent synaptic physiology cannot be ruled out, especially since separate groups of efferent neurons project in the crista to the central and peripheral zones (Purcell and Perachio 1997b). But, perhaps the most likely explanation relates to the spike encoder located in the afferent terminal (Goldberg 2000). 
Studies of the responses to externally applied galvanic currents (Goldberg et al. 1984, a,1990b; Baird et al. 1988), as well as modeling studies (Smith and Goldberg 1986), imply that encoder sensitivity is related to discharge regularity. As shown in the present study, galvanic sensitivity and efferent response magnitude grow almost identically with $\mathrm{Cv}^{*}$ suggesting that both reflect variations in encoder sensitivity. Such an explanation would be consistent with the observation that the relation between efferent response magnitude and $\mathrm{cv}^{*}$ is indistinguishable in calyx and noncalyx units since the response of calyx units to galvanic currents is not distinctive. At the same time, this cannot be the entire explanation since the various response indices $\left(F_{1}, F_{2}\right.$, and $\left.S\right)$ do not grow in the same way with $\mathrm{cv}^{*}$. The $F_{1}$ relation with $\mathrm{Cv}^{*}$ is similar to that of the overall response, but the $S$ and $F_{2}$ relations are less steep. Accepting the notion that encoder sensitivity is a major determinant of overall response magnitude, these last observations would suggest that slow responses, as well as fast-response adaptation, are more conspicuous in regular units than would be expected from their encoder sensitivities.

There would seem to be a puzzle concerning the laterality of efferent projections. Using anterograde tracers in the gerbil, Purcell and Perachio (1997b) found that efferents projecting to the contralateral crista innervated the peripheral zone, including the slopes of the crista and the ends abutting the planum semilunatum. Ipsilaterally projecting efferents could project to the central or peripheral zones. Because the central zone in the tracer experiments was exclusively supplied by ipsilateral efferents, we expected that irregular afferents, which preferentially innervate the central zone, would show small or negligible responses on stimulation of contralateral efferents. But confirming and extending results in other species (Goldberg and Fernández 1980; McCue and Guinan 1994), stimulation in the midline or on the contralateral side resulted in large responses in both calyx and noncalyx irregular afferents. On average, contralateral and midline responses were slightly smaller than ipsilateral responses. This is easily explained by the fact that contralaterally projecting efferent axons pass quite close to the ipsilateral efferent cell group (Goldberg and Fernández 1980; Purcell and Perachio 1997b) so that efferent axons from both sides should be activated during ipsilateral stimulation.

There are two ways to reconcile our results with those of Purcell and Perachio (1997b): (1) responses of irregular afferents during midline or contralateral efferent stimulation might be due to the activation of bilaterally projecting efferent neurons originating in the ipsilateral efferent cell group, or (2) such responses might be the result of the trans-synaptic ac- tivation of ipsilateral efferents. A difficulty with the first explanation is the large size of the efferent responses in question (Goldberg and Fernández 1980; McCue and Guinan 1994), yet bilaterally projecting neurons have been described as making up only a small fraction of the efferent innervation (Perachio and Kevetter 1989). Nevertheless, the possibility cannot be entirely dismissed since some workers have estimated that as many as $20-30 \%$ of efferent fibers may be bilaterally projecting (Dechesne et al. 1984; Ryan et al. 1991). In addition, such fibers, on crossing the midline, can project to central (striolar) as well as peripheral (extrastriolar) zones (Purcell and Perachio 1997a). Concerning the second possibility, it has to be emphasized that multiple shocks are needed to produce efferent responses (Goldberg and Fernández 1980) and, hence, the presence of such responses cannot be taken as definitive evidence for a monosynaptic connection between contralateral efferents and irregular afferents. Moreover, the fact that contralateral efferent responses were abolished by shallow midline lesions is hardly definitive. Besides crossing efferent axons (Lysakowski and Singer 2000), commissural fibers (Shimazu and Precht 1966) and possibly other fiber systems will be severed by such lesions.

These considerations leave open the possibility that our contralateral responses were due to the transsynaptic activation of ipsilateral efferents. We think this unlikely because, except for small differences in magnitude, efferent responses were similar for ipsilateral and contralateral stimulation. The similarities included shock thresholds and shock-frequency dependence. There can be little question that ipsilateral responses are the result of a direct activation of efferent axons. The similarity in thresholds, besides effectively ruling out the possibility of current spread from the contralateral to the ipsilateral efferent cell groups, would seem difficult to reconcile with a transsynaptic origin of the contralateral responses. Even more difficult is the finding that fast responses were as easily evoked from the contralateral as from the ipsilateral side. Fast responses from either side required high-frequency stimulation on the order of 200 shocks/s. It seems unlikely that contralateral stimulation, even at high frequency, would routinely evoke such a high-frequency trans-synaptic activation of ipsilateral efferent neurons.

At the very least, were the contralateral responses the result of trans-synaptic activation, this would raise serious methodological problems since such responses have always been interpreted as due to the direct activation of efferents (Goldberg and Fernández 1980; Guinan and Gifford 1988). Clearly, there is a need for an anatomical study repeating the experiments of Purcell and Perachio (1997b) in the chinchilla. 


\section{Fast and slow responses}

Efferent responses consist of a fast component, which builds up and decays with a time constant of $<100 \mathrm{~ms}$, and a slow component with a time constant $>10 \mathrm{~s}$ (Goldberg and Fernández 1980; McCue and Guinan 1994; the present study). The two components also differ in how they are affected by changes in shock frequency. Fast responses require high shock frequencies $(\geq 200 / \mathrm{s})$ with the result that at lower shock frequencies only slow responses are evident. Part of the difference in shock-frequency dependence no doubt reflects response kinetics since the slow component should summate the effects of successive lowfrequency shocks more effectively than the fast component. But there is an additional feature. As was emphasized in a previous study (Goldberg and Fernández 1980), the fast component shows facilitation in that the responses to successive, closely spaced shocks grow in magnitude. Facilitation is much less evident in slow responses.

One other difference concerns adaptation. During prolonged high-frequency shock trains, fast responses show a large decline. McCue and Guinan (1994) reported large declines in slow responses during prolonged stimulation with closely spaced repetitive shock trains. In fact, slow responses in the few units illustrated disappeared after $90 \mathrm{~s}$ of such stimulation. We used a similar paradigm and got different results. Many of our units showed no adaptation and in those that did the decline seldom exceeded $50 \%$. We have no explanation for the differences between the two studies. A lack of adaptation was confirmed when we used prolonged stimulation at shock frequencies low enough to evoke only slow responses. Differences in response kinetics, shock-frequency requirements, and adaptive properties suggest that slow responses would be more suited to influence tonic activity, while fast responses could serve to modify phasic responses such as might occur during rapid head movements.

In considering fast and slow responses, it has been convenient to suppose that they are entirely separate processes that summate linearly to produce an overall response. In many respects, the two components behave in this way. The one exception has to do with the buildup of the slow response. When estimated during the simultaneous presence of the fast response, the buildup has much faster kinetics than that governing the post-train decay of the slow response. The discrepancy between buildup and decay kinetics disappears when low-frequency stimulation is used to evoke a slow buildup in the absence of a fast response. The results suggest that fast and slow responses can interact nonlinearly but do not provide obvious clues as to the nature of the interaction.
Several mechanisms may underlie slow responses. Because of the slow kinetics involved, it is natural to suspect metabotropic receptors. At the same time, it should be noted that fast and slow efferent effects in the mammalian cochlea may involve the same nicotinic receptor (Sridhar et al. 1995, 1997). Efferent neurons contain CGRP (Tanaka et al. 1988, 1989; Wackym et al. 1991; Ishiyama et al. 1994) and possibly other neuroactive peptides (for review, see Goldberg et al. 1999). In lateral lines, CGRP causes a slow excitation not unlike our slow response (Sewell and Starr 1991; Bailey and Sewell 2000). Muscarinic receptors are found in the mammalian vestibular periphery (Wackym et al. 1996) and application of muscarinic agonists in the frog crista causes a slow excitation (Bernard et al. 1985). The slow responses observed in lateral lines (Sewell and Starr 1991) and in the frog crista (Bernard et al. 1985) are likely to arise presynaptically. Postsynaptic actions could be mediated by CGRP-containing efferent axons, which have been observed to contact calyces and other afferent processes (Tanaka et al. 1988; Ishiyama et al. 1994). The presence of an M current postsynaptically could provide the basis for a slow excitation since such currents are suppressed by muscarinic agonists (Fukuda et al. 1988) and the suppression can give rise to a slow EPSP (Brown 1988). KCNQ4, one of several channels that can give rise to $M$ currents (Selyanko et al. 2000), has been immunolocalized in type I hair cells and calyx endings (Kharkovets 2000). An M current has also been observed in recordings from cultured chick vestibular ganglion cells (Yamaguchi and Ohmori 1993).

\section{Functional considerations}

Electrical stimulation, such as employed here, provides a convenient starting place for the analysis of efferent actions. Yet, the resulting activation of efferent fibers is so artificial that one may question its relevance to normal function. Some reassurance has been provided by a recent study of efferent-mediated responses to head rotations (Plotnik et al. 2002). In that study, conventional responses were nulled by placing the relevant semicircular canal orthogonal to the rotation plane. The remaining responses, which are triggered by inputs to efferent pathways from canals other than the one being innervated, resemble those obtained with electrical stimulation in many ways. Both kinds of responses are exclusively excitatory, consist of fast and slow response components, and are largest in irregularly discharging fibers. Canal plugging shows that both the ipsilateral and contralateral labyrinths contribute to the efferent-mediated rotational responses. 
Efferent-mediated responses of afferents, whether these are the result of electrical or natural stimulation, are exclusively excitatory. In contrast, afferent responses to vestibular stimulation always include the increased discharge of some fibers and the decreased discharge of other fibers. Not only are efferent-mediated responses exclusively excitatory, they affect coplanar canals and otolith afferents with opposite functional polarization similarly (Goldberg and Fernández 1980; Plotnik et al. 2002; the present study). The widespread and exclusively excitatory influence of efferent actions differentiates them from purely afferent responses and would seem to preclude their acting to produce surrogate afferent signals.

Even in irregular units, efferent-mediated rotation responses are small, seldom exceeding 20 spikes/s (Plotnik et al. 2002). Large responses to electrical stimulation of efferent pathways require high, possibly unphysiological, shock frequencies (Goldberg and Fernández 1980; the present study). In regular units, efferent-mediated responses, both those to rotations and those to electrical stimulation, are quite small, typically $<10$ spikes/s. Turning first to irregular units, the fact that large, particularly fast responses require shock rates of $\geq 200$ shocks/s suggests that efferent neurons would have to fire at very high rates to produce such responses. Since efferent neurons have not been observed to fire in a sustained manner at such high rates (Marlinsky 1995), large efferentmediated fast responses would presumably depend on high-frequency bursts in efferent neurons and would happen only episodically. This raises the question as to the conditions that might trigger such high-frequency bursts. One suggestion is that efferent responses could be tied to active head movements either by an efference copy or a reafference signal (Goldberg and Fernández 1980; Highstein 1991). Supporting this notion were observations in lateral lines (Russell 1971; Roberts and Russell 1972) and the toadfish vestibular system (Highstein and Baker 1986; Boyle and Highstein 1990) that efferent neurons fired in anticipation of movement. Such an efferent response would presumably modify the afferent discharge caused by active compared with passive head movements. However, in a recent study, no differences in afferent discharge were observed when active and passive head movements were compared (Cullen and Minor 2002).

Slow responses provide a means for the efferent system to alter the background discharge of afferents. Efferent neurons can discharge up to 100 spikes/s (Marlinsky 1995). In this frequency range, the efferent responses of irregular units are typically 5-20 spikes/s (Goldberg and Fernández 1980) (see Fig. 7, the present study). While small compared with the afferent responses to large, rapid head movements, such an effect would result in a relatively large modulation of the background discharge, which in irregular units in the chinchilla is typically 40-60 spikes/s. That the efferent system can exert a slow but powerful influence on afferent discharge is indicated by the presence in decerebrate preparations of large oscillations in the background discharge, which are likely to reflect a positive feedback loop between the vestibular organs and central vestibular neurons (Plotnik et al. 2002). Although the oscillations are likely to be an artifact of decerebration, they indicate that in the absence of electrical stimulation the efferent system can have a much larger effect on afferent discharge than hitherto expected.

Only small efferent responses are seen in regular afferents. This is so for electrical stimulation (Goldberg and Fernández 1980), for efferent-mediated rotational responses (Plotnik et al. 2002), and for slow oscillations (M. Plotnik, V. Marlinski, and J.M. Goldberg, unpublished observations). Were the only function of efferents to modify spike discharge on a reltively rapid time scale, it would be difficult to understand why the peripheral zones of the cristae and maculae, the regions where regular afferents reside (Baird et al. 1988; Goldberg et al. 1990a,b), receive so dense an efferent innervation (Nomura et al. 1965; Lysakowski and Goldberg 1997; Purcell and Perachio 1997b). The results for regular units suggest that the efferent system is involved in functions besides the immediate modification of afferent discharge. A challenge of future research will be to discern potentially long-lasting influences of efferent modulation, including effects other than alterations in afferent spike activity.

\section{ACKNOWLEDGMENTS}

The authors thank Dr. Tomomi Fukuchi-Shimogori for technical assistance and Drs. Anna Lysakowski and Chris Holt for commenting on a previous version of the manuscript. The research was supported by the National Institute of Deafness and Other Communicative Disorders Grant DC 03946.

\section{REFERENCES}

Art JJ, Fettiplace R, Fuchs PA. Synaptic hyperpolarization and inhibition of turtle cochlear hair cells. J. Physiol. 356:525-550, 1984.

Ashmore JF, Russell IJ. Effects of efferent nerve stimulation on hair cells of the frog sacculus. J. Physiol. 329:25-26, 1982.

BAILEY GP, SEWELL WF. Calcitonin gene-related peptide suppresses hair cell responses to mechanical stimulation in the Xenopus lateral line organ. J. Neurosci. 20:5163-5169, 2000.

Baird RA, Desmadryl G, Fernández C, Goldberg JM. The vestibular nerve of the chinchilla. II. Relation between afferent response 
properties and peripheral innervation patterns in the semicircular canals. J. Neurophysiol. 60:182-203, 1988.

Bernard C, Cochran SL, Precht W. Presynaptic actions of cholinergic agents upon the hair cell-afferent fiber synapses in the vestibular labyrinth of the frog. Brain Res. 338:225-236, 1985.

BobBin RP, Konishi T. Acetylcholine mimics crossed olivocochlear bundle stimulation. Nature 231:222-223, 1971.

Bobbin RP, Konishi T. Action of cholinergic and anticholinergic drugs at the crossed olivochlear bundle-hair cell junction. Acta Otolaryngol. 77:55-65, 1974.

Boyle R, Highstein SM. Efferent vestibular system in the toadfish: action upon horizontal semicircular canal afferents. J. Neurosci. 10:1570-1582, 1990.

Boyle R, Carey JP, Highstein SM. Morphological correlates of response dynamics and efferent stimulation in horizontal semicircular canal afferents of the toadfish, Opsanus tau. J. Neurophysiol. 66:1504-1521, 1991.

BRICHTA AM, Goldberg JM. Responses to efferent activation and excitatory response-intensity relations of turtle posterior-crista afferents. J. Neurophysiol. 83:1224-1242, 2000.

Bridgeman D, Hoffman L, Wackym PA, Micevych PE, Popper P. Distribution of choline acetyltransferase mRNA in the efferent vestibular neurons of the chinchilla. J. Vestib. Res. 6:203-212, 1996.

BRown DA. M currents: an update. Trends Neurosci. 11:294-299, 1988.

CuLLEN KE, Minor LB. Semicircular canal afferents similarly encode active and passive head-on-body rotations: implications for the role of vestibular efference. J. Neurosci. 22:RC226, 2002.

Dechesne C, Raymond J, Sans A. The efferent vestibular system in the cat: a horseradish peroxidase and fluorescent retrograde tracers study. Neuroscience. 1:893-901, 1984.

Elgoyhen AB, Vetter DE, Katz E, Rothlin CV, Heinemann SF, Boulter J. Alpha10: a determinant of nicotinic cholinergic receptor function in mammalian vestibular and cochlear mechanosensory hair cells. Proc. Natl. Acad. Sci. USA 98:35013506, 2001.

Fernández C, Baird RA, Goldberg JM. The vestibular nerve of the chinchilla. I. Peripheral innervation patterns in the horizontal and superior semicircular canals. J. Neurophysiol. 60:167-181, 1988.

Fernández C, Goldberg JM, Baird RA. The vestibular nerve of the chinchilla. III. Peripheral innervation patterns in the utricular macula. J. Neurophysiol. 63:767-780, 1990.

Fernández C, Lysakowski A, Goldberg JM. Hair-cell counts and afferent innervation patterns in the cristae ampullares of the squirrel monkey with a comparison to the chinchilla. J. Neurophysiol. 73:1253-1269, 1995.

Flock A, Russell IJ. The post-synaptic action of efferent fibres in the lateral line organ of the burbot Lota lota. J. Physiol. 235:591$605,1973$.

Flock Å, Russell IJ. Inhibition by efferent nerve fibres: action on hair cells and afferent synaptic transmission in the lateral line canal organ of the burbot Lota lota. J. Physiol. 257:45-62, 1976.

Fuchs PA, Murrow BW. Cholinergic inhibition of short (outer) hair cells of the chick's cochlea. J. Neurosci. 12:800-809, 1992a.

Fuchs PA, Murrow BW. A novel cholinergic receptor mediates inhibition of chick cochlear hair cells. Proc. R. Soc. Lond. B Biol. Sci. 248:35-40, 1992b.

Fukuda K, Higashida H, Kubo T, Maeda A, Akiba I, Bujo H, Mishina M, Numa S. Selective coupling with $\mathrm{K}+$ currents of muscarinic acetylcholine receptor subtypes in NG108-15 cells. Nature 335:355-358, 1988.

Furukawa T. Effects of efferent stimulation on the saccule of goldfish. J. Physiol. 315:203-215, 1981.

GACEK RR. Efferent component of the vestibular nerve. In: Rasmussen GL, Windle WF (Eds) Neural mechanisms of the audi- tory and vestibular systems. Thomas, Springfield. IL, pp 276284, 1960.

GACEK RR, LyON M. The localization of vestibular efferent neurons in the kitten with horseradish peroxidase. Acta Otolaryngol. 77:92-101, 1974.

GoldBerg JM. Afferent diversity and the organization of central vestibular pathways. Exp. Brain Res. 130:277-297, 2000.

GOLdBERg JM, FERNÁNDEZ C. Responses of peripheral vestibular neurons to angular and linear accelerations in the squirrel monkey. Acta Otolaryngol. 80:101-110, 1975.

Goldberg JM, Fernández C. Efferent vestibular system in the squirrel monkey: anatomical location and influence on afferent activity. J. Neurophysiol. 43:986-1025, 1980.

Goldberg JM, Smith CE, Fernández C. Relation between discharge regularity and responses to externally applied galvanic currents in vestibular nerve afferents of the squirrel monkey. J. Neurophysiol. 51:1236-1256, 1984.

Goldberg JM, Desmadryl G, Baird RA, Fernández C. The vestibular nerve of the chinchilla. IV. Discharge properties of utricular afferents. J. Neurophysiol. 63:781-790, 1990a.

Goldberg JM, Desmadryl G, Baird RA, Fernández C. The vestibular nerve of the chinchilla. V. Relation between afferent discharge properties and peripheral innervation patterns in the utricular macula. J. Neurophysiol. 63:791-804, 1990b.

Goldberg JM, Brichta AM, WACKYM PW. Efferent vestibular system: anatomy, physiology and neurochemistry. In: Anderson JH, Beitz AJ (Eds) Neurochemistry of the Vestibular System. CRC Press, Boca Raton, FL, pp 61-94, 1999.

GuinAn JJ Jr, GifFord ML. Effects of electrical stimulation of efferent olivocochlear neurons on cat auditory-nerve fibers. I. Rate-level functions. Hear. Res. 33:97-113, 1988.

Highstein SM. The central nervous system efferent control of the organs of balance and equilibrium. Neurosci. Res. 12:13-30, 1991.

Highstein SM, Baker R. Organization of the efferent vestibular nuclei and nerves in the toadfish, Opsanus tau. J. Comp. Neurol. 243:309-325, 1986.

Holt JC, Xue J-T, Goldberg JM. Synaptic mechanisms underlying afferent responses to efferent activation in the turtle posterior crista. Assoc. Res. Otolaryngol. Abstr. 26:33, 2003.

IsHIYAMA A, LóPEz I, WACKYM PA. Subcellular innervation patterns of the calcitonin gene related peptidergic efferent terminals in the chinchilla vestibular periphery. Otolaryngol. Head Neck Surg. 111:385-395, 1994.

Iurato S, Luciano L, Pannese E, Realse E. Efferent vestibular fibers in mammals: morphological and histochemical aspects. Prog. Brain Res. 37:429-443, 1972.

Kharkovets T, Hardelin J-P, Safieddine S, Schweizer M, El-Amraoui A, Petit C, Jentsch TJ. KCNQ4, a $\mathrm{K}^{+}$channel mutated in a form of dominant deafness, is expressed in the inner ear and the central auditory pathway. Proc. Natl. Acad. Sci. USA 97:43334338, 2000.

Kashi S, Sasa M, Matsuoka I, Ito J, Takaori S. Inhibition of vestibular nerve activity by efferent fibres in the cat. Acta Otolaryngol. 104:13-21, 1987.

LiNDEMAN HH. Studies on the morphology of the sensory regions of the vestibular apparatus. Ergebn. Anat. Entwickl. 42:1-113, 1969.

LySAKOWSKI A. Synaptic organization of the crista ampullaris in vertebrates. Ann. N. Y. Acad. Sci. 781:164-182, 1996.

LySAKOWSKI A, GOLdBERG JM. A regional ultrastructural analysis of the cellular and synaptic architecture in the chinchilla cristae ampullares. J. Comp. Neurol. 389:419-443, 1997.

Lysakowski A, Singer M. Nitric oxide synthase localized in a subpopulation of vestibular efferents with NADPH diaphorase histochemistry and nitric oxide synthase immunohistochemistry. J. Comp. Neurol. 427:508-521, 2000. 
Lysakowski A, Minor LB, Fernández C, Goldberg JM. Physiological identification of morphologically distinct afferent classes innervating the cristae ampullares of the squirrel monkey. J. Neurophysiol. 73:1270-1281, 1995.

Marco J, Lee W, Suarez C, Hoffman L, Honrubia V. Morphologic and quantitative study of the efferent vestibular system in the chinchilla: 3-D reconstruction. Acta Otolaryngol. 113:229-234, 1993.

MARLINSKY VV. The effect of somatosensory stimulation on secondorder and efferent vestibular neurons in the decerebrate decerebellate guinea-pig. Neuroscience 69:661-669, 1995.

McCue MP, Guinan J Jr. Influence of efferent stimulation on acoustically responsive vestibular afferents in the cat. J. Neurosci. 14:6071-6083, 1994.

Meredith GE. Comparative view of the central organization of afferent and efferent circuitry for the inner ear. Acta Biol. Hung. 39:229-249, 1988.

Morrison DF. Multivariate Statistical Methods, 3rd ed. McGraw-Hill, New York, 1990

Nomura Y, Gacek RR, Balogh KJ. Efferent innervation of vestibular labyrinth. Arch. Otolaryngol. 81:335-339, 1965.

Oliver D, Klocker N, Schuck J, Baukrowitz T, Ruppersberg JP, FaKLER B. Gating of $\mathrm{Ca}^{2+}$-activated $\mathrm{K}+$ channels controls fast inhibitory synaptic transmission at auditory outer hair cells. Neuron 26:595-601, 2000.

Perachio AA, Kevetter GA. Identification of vestibular efferent neurons in the gerbil: histochemical and retrograde labelling. Exp. Brain Res. 78:315-326, 1989.

Plotnik M, Marlinski V, Goldberg JM. Reflections of efferent activity in rotational responses of chinchilla vestibular afferents. J. Neurophysiol. 88:1234-1244, 2002.

Purcell IM, Perachio AA. Bilaterally projecting vestibular efferent neurons in the gerbil. Assoc. Res. Otolaryngol. Abstr. 20:141, 1997a.

Purcell IM, Perachio AA. Three-dimensional analysis of vestibular efferent neurons innervating semicircular canals of the gerbil. J. Neurophysiol. 78:3234-3248, 1997b.

Rasmussen GL. The olivary peduncle and other fiber connections of the superior olivary complex. J. Comp. Neurol. 84:141-219, 1946.

Roberts BL, Russell IJ. The activity of lateral line efferent neurones in stationary and swimming dogfish. J. Exp. Biol. 57:433-448, 1972.

Rossi ML, Prigioni I, Valli P, Casella C. Activation of the efferent system in the isolated frog labyrinth: effects on the afferent EPSPs and spike discharge recorded from single fibres of the posterior nerve. Brain Res. 185:125-137, 1980.

Rossi ML, Martini M, Pelucchi B, Fesce R. Quantal nature of synaptic transmission at the cytoneural junction in the frog labyrinth. J. Physiol. 478:17-35, 1994.

Russell IJ. The role of the lateral-line efferent system in Xenopus laevis. J. Exp. Biol. 54:621-641, 1971.

Ryan AF, Simmons DM, Watts AG, Swanson LW. Enkephalin mRNA production by cochlear and vestibular efferent neurons in the gerbil brainstem. Exp. Brain Res. 87:259-267, 1991.

SALA O. The efferent vestibular system. Electrophysiological research. Acta Otolaryngol. Suppl. (Stockh.) 197:1-34, 1965.

Selyanko AA, Hadley JK, Wood C, Abogadie C, Jentsch TJ, Brown DA. Inhibition of KCNQ1-4 potassium channels expressed in mammalian cells via $\mathrm{M}_{1}$ muscarinic acetylcholine receptors. J. Physiol. 522:349-355, 2000.

SeWEll WF, Starr PA. Effects of Calcitonin gene-related peptide and efferent nerve stimulation on afferent transmission in the lateral line organ. J. Neurophysiol. 65:1158-1169, 1991.

Shimazu H, Precht W. Inhibition of central vestibular neurons from the contralateral labyrinth and its mediating pathway. J. Neurophysiol. 29:467-492, 1966.

Smith C, Goldberg JM. A stochastic afterhyperpolarization model of repetitive activity in vestibular afferents. Biol. Cybern. 54:41-51, 1986.

Smith CA, Rasmussen GL. Nerve ending in the maculae and cristae of the chinchilla vestibule, with a special reference to the efferents. The Third Symposium on the Role of the Vestibular Organs in Space Exploration. NASA SP-152. U.S. Government Printing Office, Washington DC, pp 183-201, 1968.

Sridhar TS, Liberman MC, Brown MC, Sewell WF. A novel cholinergic "slow effect" of efferent stimulation on cochlear potentials in the guinea pig. J. Neurosci. 15:3667-3678, 1995.

SRIDHAR TS, Brown MC, SeWELl WF. Unique postsynaptic signaling at the hair cell efferent synapse permits calcium to evoke changes on two time scales. J. Neurosci. 17:428-437, 1997.

Sugai T, Sugitani M, Ooyama H. Effects of activation of the divergent efferent fibers on the spontaneous activity of vestibular afferent fibers in the toad. Jpn. J. Physiol. 41:217-232, 1991.

Tanaka M, Takeda N, Senba E, Tohyama M, Kubo T, Matsunaga T. Localization of calcitonin gene-related peptide in the vestibular end-organs in the rat: an immunohistochemical study. Brain Res. 447:175-177, 1988

Tanaka M, Takeda N, Senda E, Tohyama M, Kubo T, Matsunaga T. Localization, origin and fine structure of calcitonin gene related peptide-containing fibers in the vestibular end-organs of the rat. Brain Res. 504:31-35, 1989.

Wackym PA, Popper P, Ward PH, Micevych PE. Cell and molecular anatomy of nicotinic acetylcholine receptor subunits and calcitonin gene-related peptide in the rat vestibular system. Otolaryngol. Head Neck Surg. 105:493-510, 1991.

Wackym PA, Chen CT, Ishiyama A, Pettis RM, Lopez IA, Hoffman L. Muscarinic acetylcholine receptor subtype mRNAs in the human and rat vestibular periphery. Cell Biol. Int. 20:187-192, 1996.

WARR WB. Olivocochlear and vestibular efferent neurons of the feline brain stem: their location, morphology and number determined by retrograde axonal transport and acetylcholinesterase histochemistry. J. Comp. Neurol. 161:159-182, 1975.

Weisstaub N, Vetter DE, Elgoyhen AB, Katz E. The alpha9alpha10 nicotinic acetylcholine receptor is permeable to and is modulated by divalent cations. Hear. Res. 167:122-135, 2002.

WersäLl J, BAGGER-SJöBÄCK D. Morphology of the vestibular sense organ. In: Kornhuber HH (Ed) Handbook of Sensory Physiology, Vestibular System. Basic Mechanisms Vol. VI, part 1. Springer-Verlag, Berlin, pp 123-170, 1974.

Wiederhold ML, KIANG NYS. Effects of electrical stimulation of the crossed olivocochlear bundle on single auditory nerve-fibers in the cat. J. Acoust. Soc. Am. 48:950-965, 1970.

Yamaguchi K, Ohmori H. Suppression of the slow $\mathrm{K}^{+}$current by choline agonists in cultured chick cochlear ganglion cells. J. Physiol. 464:213-228, 1993. 